DIVISION OF THE HUMANITIES AND SOCIAL SCIENCES

CALIFORNIA INSTITUTE OF TECHNOLOGY

PASADENA, CALIFORNIA 91125

THE ALLOCATION OF A SHARED RESOURCE WITHIN AN ORGANIZATION

John O. Ledyard

Charles Noussair

Purdue University

David Porter

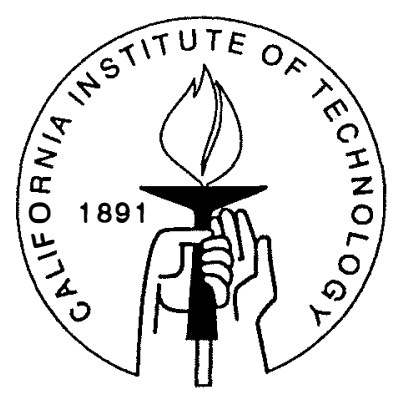

SOCIAL SCIENCE WORKING PAPER 917

January 1995 


\title{
THE ALLOCATION OF A SHARED RESOURCE WITHIN AN ORGANIZATION
}

\author{
John O. Ledyand Charles Noussair David Porter
}

\begin{abstract}
Many resources such as supercomputers, legal advisors, and university classrooms are shared by many members of an organization. When the supply of shared resources is limited, conflict usually results between contending demanders. If these conflicts can be adequately resolved, then value is created for the organization. In this paper we use the methodology of applied mechanism design to examine alternative processes for the resolution of such conflicts for a particular class of scheduling problems. We construct a laboratory environment, within which we evaluate the outcomes of various allocation mechanisms. In particular, we are able to measure efficiency, the value attained by the resulting allocations as a percentage of the maximum possible value. Our choice of environment and parameters is guided by a specific application, the allocation of time on NASA's Deep Space Network, but the results also provide insights relevant to other scheduling and allocation applications. We find (1) experienced user committees using decision support algorithms produce reasonably efficient allocations in lower conflict situations but perform badly when there is a high level of conflict between demanders, (2) there is a mechanism, called the Adaptive User Selection Mechanism (AUSM) which charges users for time, which yields high efficiencies in high conflict situations but because of the prices paid, the net surplus available to the users is less than that resulting from the inefficient user committee (a reason why users may not appreciate "market solutions" to organization problems) and (3) there is a modification of AUSM in which tokens, or internal money, replaces real money, which results in highly efficient allocations without extracting any of the users' surplus. Although the distribution of surplus is still an issue, the significant increase in efficiency provides users with a strong incentive to replace inefficient user committees with the more efficient AUSM.
\end{abstract}




\section{THE ALLOCATION OF A SHARED RESOURCE WITHIN AN ORGANIZATION*}

Johrı O. Ledyard

\author{
David Porter
}

\author{
Charles Noussair
}

\section{Introduction}

Typically, shared resources are centrally financed and managed by an organization and used in various ways and intensities by diverse members of that organization. Examples of such resources include supercomputers, observatories, motor pools, legal advisors, lab facilities, etc. The methods and processes by which shared resources arc allocated often evolve in a common pattern. We offer our stylized version here. ${ }^{1}$ In the beginning, the resource is proposed by potential uscrs, designed by engineers, and financed and managed by burcaucrats. Many of these actors have a political stake in the performance and utility of the resources: thus, they want to keep control. The initial management structure is of ten a combination of user committees and bureaucratic responsibility. As long as desired use is not

'The authors thank the Implementation Development Office of the Jet Propulsion Laboratory of NASA for their financial support.

${ }^{1}$ For a more extensive review of management approaches see Ostrom (1990). 
much larger than capacity, committec meetings and bureaucratic negotiation can usually overcome what little conflicts may arise in determining who gets what use of the shared facility. However, increases in demand or decreases in usable capacity can easily lead to congestion in the system and to contentious non-negotiable conflicts among users. If it is not possible, or is costly to expand the rcsources, the next step usually involves asking users and bureaucrats to streamline their decision processes. Decision Support Teams are often summoned to help facilitate the process. They provide computer programs (sometimes involving various voting mechanisms) which are intended to speed up the existing processcs. Using valuation and resource requirement information provided by the users, the algorithms may heuristically solve very complex optimization problems in an attempt to compute good allocations. Unfortunately, these support programs tend to ignore the fact that users have incentives to bias the information they provide to the algorithm in order to achicve more favorable allocations. The new support systems work faster but congestion remains as much of a problem as before. Value is foregonc.

At this point, in desperation, economists are sometimes called for advice. Their usual response is "auction it off" or "price it at marginal cost", forgetting at least two facts that lead users to ignore the economists' advice. First, users who have been getting something for nothing will now have to pay to obtain an allocation. Thus, even if allocative efficiency improves and value increases, the users can be worse off because the bureaucracy may capturemore in rents than the increase in the value of the allocations. So the users will use whatever political clout they have to block these "economic solutions". Second, even if the political resistance can be overcome, for example by the use of grandfathered allocations ${ }^{2}$, these scheduling problems can involve significant non-convexities which causc prices to be unable to function as coordinating deviccs. Thus even if the cconomists' advice is taken seriously, the results may be less than satisfactory and yield allocations no better for users than current processes are producing (see Banks, Ledyard and Porter (1989)).

In this paper we explore a dif(erent approach to finding solutions for congestion in shared resources: applied mechanism design. (See Ledyard (1993)

\footnotetext{
${ }^{2}$ An interesting example of this can be found in Riker and Sened (1991) based on work of Grether, Isaac and Ploll (1981).
} 
for a summary of the approach.) Wc argue that new processes can be designed which improve on congested user committees or other regulatory administrative procedures. The constraints on the design process, in addition to those familiar to economists such as incentive compatibility and budget balancing, include limits on the computational capability of any algorithm used and political constraints which must be satisfied if the mechanism is to be acceptable to the parties involved as a replacement to current procedures. This approach to the design of new mechanisms is ideally pursued by the combination of theorists, who can analyze some of the properties of an allocation mechanism, and experimental economists, who use the laboratory to test the performance and refine the procedures for demonstration and actual use. When theoretical knowledge is not sufficient to describe the behavior of individuals in a mechanism in the environment under study, the economist can still create new mechanisms, the choice guided by theoretical intuition and previous empirical evidence from other environments. The laboratory can then be used to test and improve the performance of the new mechanism in an environment based on the field application of interest. This approach to design is similar in spirit to the aircraft designer who uses wind tunnels to create new airplanes.

In this paper, we report the results from a set of experiments designed to provide a testbed and a demonstration of proof of concept. We based our experiments on a systematic study of a specific sharcd resource problem, the allocation of tracking time of NASA's ivorldivide Deep Space Network (DSN) of antennas. While onc may or may not be interested in the DSN allocation problem, the approach we take and the results of our performance tests have a wide range of application to scheduling and other allocation problems.

Our approach is straightforivard to replicate. We first try to extract those elements of the situation that are most relevant to the mechanism design problem. For the DSN problem, we report this aspect of our research in sections 2 and 3 below. Using these historical and theoretical analyses, we then crcate a class of environments, our wind tunnel parameters, within which to test various orgmization designs. Next, we try to construct an experimentally testable version of the current process as a benchmark against which to test now designs. Then we create, being guided by relevant theory and experimental evidence, new mechanisms which we think will solve the allocation problem. Finally, we test the mechanisms in the environments. At this point we can eliminate designs with obviously poor performance and can 
fine tune the procedurcs (including stopping rules, information structures, etc.) that seem promising. The results of this experimental analysis are contained in Section 6. We conclude with a summary of lessons learned.

We turn now to the details.

\section{A Little Background}

The Deep Space Network is a worldivide network of antennas managed by the Jet Propulsion Laboratory (JPL) for NASA. The network is used to provide uplink and downlink communication with spacecraft in deep space. There are currently 10 flight projects in deep space using the network, 4 ground based radio/radar astronomy projects and maintenance activities, 3 planned missions, and 5 pre-planning stage missions which will require use of the antennas. The antennas are located at three different locations which allows for continuous tracking of a spacecraft and there are three types of antennas (34 meter High Efficicncy, 34 meter beam waveguide, and 70 meter) at each location. Each antenna may be directed to at most one user at a time. Demand varies greatly among users and across their lifetimes. For example, the Voyager and Pioneer missions are over 15 years old, have completed their prime missions, and are now in an extended mission mode at the outer reaches of our solar system; on the other hand, the Galileo mission to Jupiter and Ulysses solar polar mission are still en route to their prime targets. In addition, demands are interrelated since the goal of the organization is overall mission success. Thereforc, scheduling in this environment is a very dynamic process.

Scheduling of the antenna time has beeri facilitated by the use of a decision support system and a series of user committees. There are currently the equivalent of 15 full time employees involved in constructing and updating time schedules, which tentatively assign each antenna beginning ten years in advance. For two ycars in advance, detailed minute by minute schedules are provided which can be edited until the date scheduled. Heuristic look ahead algorithms help with the provision of initial schedules and aid long-term planning. However, despite the amount of resources used in the scheduling process, there remains widespread contention for resources and significant amounts of committce time used to resolve schedule conflicts. Recently, some effort has been made t,o commit to resource "allocations" early 
so that projects can plan carly. However, there is still an oversubscription of resources and changes are commonplace. Below we provide a simple flowchart of the current committce allocation process.

|Figure 1. about here|

\section{A Theoretical Framework}

The DSN is an cxample of a shared resource. The abstract structure of the allocation problem associated with shared resources is very straight-forward. There is a set, $X$, of resources to be allocated. Examples include time on an antenna, a computer memory, volume in the bay of a space shuttle, time with a consultant, the draw of power from a shared battery, or broadcasting over a particular spectrum biund in a specific gcographic arca. There are a set of potential users of thesc resources, $l=\{1, \ldots, n\}$. A feasible allocation assigns a subset $X_{i} \subseteq X$ to each $i$ so that the collection of sets $X_{0}, X_{1}, \ldots X_{n}$ is a partition ${ }^{3}$ of $X$. In some cases there is a natural obvious partition, as for example with rooms in a dormitory, and in other cases there is not, as in time on an antenna. Uscrs get utility or profits from each subset which we denote $U^{i}\left(X_{i}\right)$. Wc will assume throughout that a user's total utility is $U^{i}\left(X_{i}\right)-y_{i}$ where $y_{i}$ is the money paid to reccive the use of $X_{i}$. An efficient feasible allocation $a=\left(\lambda_{1}, \ldots, \lambda_{n}\right)$ is one such that there is no other feasible allocation $a^{\prime}=\left(X_{1}^{\prime}, \ldots X_{n}^{\prime}\right)$ such that $\sum_{i=1}^{n} U^{i}\left(X_{i}^{\prime}\right)>\sum_{i=1}^{n} U^{i}\left(X_{i}\right)$. Thus, an efficient allocation solves

$$
\begin{gathered}
\max _{X_{1}, \ldots . X_{n}} \sum_{i} U^{i}\left(X_{i}\right) \\
\text { subject to } \bigcup_{i=1}^{n} X_{i} \subseteq X \\
\text { and } X_{i} \cap X_{j}=\emptyset \forall i, j \in I .
\end{gathered}
$$

If the $C_{i}(\cdot)$ were known. this would be a complex non-linear computation which, in principle. could loe solved or approximaled. One might be tempted to simply turn it over to the operations research department. The only diffculties would be computational complexities. However, in many applications

\footnotetext{
${ }^{3} \bigcup_{i=0}^{N} X_{i}=X^{\prime}$ and $X_{i} \cap X_{j}=\emptyset$ for all $i, j \in I . X_{0}$ is the subset of unassigned resources.
} 
the users want to maximi\%: their own intercsts and not those of the group. Therefore, getting accurate information on $U^{i}$ becomes a problem. Standard algorithms ask for data on $U^{i}$ but the distortions created by incentive compatibility constraints may actually lead the algorithms to choose allocations with $\sum_{i} U_{i}\left(x_{i}\right)$ significantly less than the maximum possible.

Setting up markets is an alternative often mentioned. Here a market would be organized for each $x \in \mathcal{X}$, with a price $p(x) \in R$, so that $i$ would pay $\int_{x_{i}} p(x) d x$ for the set. $x_{i}$. For problems like ours, if a market equilibrium exists, the prices would support the solution. That is, for all $i$ and all $X_{i}^{\prime}, U^{i}\left(X_{i}^{o}\right)-\int_{X_{i}^{o}} p(x) d l x \geq U^{i}\left(X_{i}^{\prime}\right)-\int_{X_{i}^{\prime}} p(x) d x$ where $X_{i}^{o}$ is the optimal allocation.

Unfortunately, therc are many problems for which such a market equilibrium does not exist. No such function $p(x)$ exists. The classic example is found in Koopmans and Beckman (1957). Another example is in Banks, Ledyard, and Porter (1989). In these cases, one might imagine pricing subsets $X_{i}$ rather than elements.$v$ (sce, c.y., Papai (199il)). This can sometimes create an equilibrium at the cost of creating $2^{|.|} \mid$markets, each of which could be very thin. Not much is known about the performance of markets when $X$ has a complex, non-convex structure.

When algorithms and markets will not work very ivell, some success has been realized using a special type of ascending bid auction. These auction mechanisms are relatively easy to understand and achieve fairly high efficiencies. They are called AUSM (Adaptive User Selection Mechanisms). The basic components of AUSM include: (i) a bid, $\left(A^{i}, b^{i}\right)$, where $A \subseteq X$ and $b \in R$, read as $i$ bids $b^{i}$ to recoive $A^{i}$, and (ii) a provisional allocation, $\left(X_{0}, X_{1}, \ldots, X_{n}\right)$, where $X_{i}$ is composed of provisionally accepted bids and $X_{i}=\bigcup_{k} A^{i k}$. The ascending bid uature of the mechanism comes from the rule which determines whether any new bid is to be included in the provisional allocation and which bids are then to be removed. This revision rule is simple: $\left(A^{i *}, b^{i *}\right)$ is accepted if $b^{i *}>\sum_{j k \in z} b^{j k}$ where $z=\left\{j k \mid A^{j k} \cap A^{i *} \neq \emptyset\right\}$. That is $i$ must agrce to pay at least as much as those who will be displaced if $i$ 's bid is accepted. With this rulc, the sum of the accepted bids $\sum_{j k} b^{j k}$ is always increasing. The continuous version of AUSM allows bids to be submitted at any time with a rule that specifies when bidding stops. This form of the process is computationally simple but it docs leave open the possibility that users who only want, small subscts may have difficulty' displacing users who have successfully bid for a large subsel. This problem has been addressed 
by adding a standby queue, described in Banks, Ledyard, and Porter (1989) and below in Section 4.2. The queue appears to work reasonably well but it is possible that another design would be better. That remains an open question.

To summarize, the generic problem facing the mechanism designer for a given environment $X$ is to find a process which produces allocations (partitions) with high values of $\sum_{i} U_{i}\left(x_{i}\right)$. For our DSN problem, $X$ is a collection of heterogeneous items called slots numbered $j=1, \ldots J$ which can be occupied by one and only one user. This is a one to many assignment problem. The relevant optimization problem for DSN is described in Section 4.3. We now turn to that specific example of a shared resource problem.

\section{Our Laboratory Environment}

\subsection{Supply}

The commodities to be allocated are called slots. Each slot is completely specified by a resource and a time. Let $S$ denote the set of slots and $s_{m t} \in S$ denote the slot on resource $m$, at time t. There are $M$ resources and $T$ times, where $\mathrm{m}=(1, \ldots, \mathrm{M})$ and $\mathrm{t}=(1, \ldots, \mathrm{T})$. The slots can be represented by an $\mathrm{M}$ $\mathrm{x} \mathrm{T}$ matrix as in Figure 2. Let $P_{j}$ denote package $\mathrm{j}$, where $P_{j} \subset S$ and let $j=1, \ldots, J$ where $J=2^{M T}-1$. Any collection of slots can be considered a package. In the experimental testbed we developed, $M=2$ and $T=10$ so that there are 20 slots to be allocated and $2^{20}-1$ possible packages. This is shown in Figure 2.

[Figure 2. about here]

\subsection{Demand}

All subjects in the experiments are demanders. There are $I$ demanders, denoted by $i=(1, \ldots, I)$, each of whom has a private valuation for each package. Let $V_{i j}$ denote demander $i$ 's valuation for package $j$. The valuation indicates the monetary value demander $i$ will receive if $i$ obtains all of the slots in the package. $V_{i j}$ is given in terms of an experimental currency, which is called "francs." At the end of each experimental session, subjects are paid 
an amount of U.S. dollars proportional to the total amount of francs they earn by obtaining packages of slots. In this way, valuations are induced, so that subjects have a monetary incentive to maximize the total number of francs they earn. ${ }^{4}$

In choosing a set of demanders' types, or utility functions, we tried to capture the general qualities of the requirements of the DSN users, while keeping the types simple and the number of types small. We decided on the following four generic types of demand structures.

1. Contiguous: A contiguous demander values packages that are composed of slots at adjacent times on the same resource. Often, users of the DSN require long periods of continuous coverage during important phases of their mission; for example, when mapping a planet or repairing an antenna. In the experiment, contiguous demanders must obtain the same resource for at least two times in a row to receive any value. Thus, values for contiguous packages are superadditive.

2. Periodic: A periodic demander values packages that are composed of times separated by a fixed interval on the same resource. Some users of the DSN require contact with their spacecraft at regular time intervals. For example, Pioneer 10 must be contacted at least once every 36 hours to readjust its communications equipment in order to guarantee future contact. In our experimental design, periodic demanders need to use slots on the same resourcespaced at five time slots apart or otherwise their value is zero. This is an example of nonconvexity in the demand structure.

3. Array: An array demander values packages that are composed of slots at the same time on multiple resources. Often, it may be desirable to point two antennae in the same direction in order to increase the data return rate. An example of this occurs during an encounter when all instruments want to be sending data using the 70 meter antenna and the 34 meter antennas at the same location simultancously allow for a higher data transmission rate with lower error (data loss) rates. In our design, array demanders require tivo resources at the same time.

\footnotetext{
${ }^{4}$ See Smith (1976) for more on the theory of induced valuation.
} 
4. Maintenance: A maintenance demander values as many single slot packages on resources as he can acquire. This is a representation of the preferences of the DSN maintenance staff who are largely indifferent about the time the antenna is shut down for maintenance.

One feature of the information structure in the DSN environment is the common knowledge of the times of day at each location which can be of use to demanders (all users know when each project is on the same side of the earth as a particular antenna complex). These times are referred to as a spacecraft vieuperiod. In the experiments, each demander was assigned one of two possible viewperiods, and the number of demanders with each viewperiod was known to all subjects. Subjects possessing viewperiods 1 and 2 had a zero valuation for any slot in times (columns) 1, 2, 6, or 7 (for viewperiod 1 ) or in times $4,5,9$, and 10 (for viewperiod 2 ) respectively.

In each of our experimental sessions, there were six demanders. Demanders did not know the valuations of any other demanders, but they knew that there were a total of three subjects possessing each viewperiod. They also knew the set of possible types, but not the exact valuations which demanders of the various types would have. Each demander was assigned an identification number, one of the four types discussed above and one of the two possible viewperiods. The following figure relates the identification numbers, the types, and the viewperiods.

[Figure 3. about here]

\subsection{Schedule}

A schedule is an assignment of slots to demanders. A schedule is feasible if it satisfies:

$$
\sum_{i \in I} \sum_{j \in C_{m} t} X_{i j} \leq 1 ; \forall m, t
$$

and

$$
X_{i j} \in\{0,1\}
$$

where $C_{m t} \subset J$ is the set of packages that contain slot $s_{m t}$ and $X_{i j}=1$ if demander $i$ receives package $j$ and zero otherwise. A slot can be included in at most one package that is allocated. Each package can be allocated to at 
most one demander. Also, a slot cannot be subdivided but must be assigned in its entirety. A schedule is eflicient if it solves:

$$
\max \sum_{i \in l} \sum_{j \in J} V_{i j} X_{i j}
$$

subject to equations (1) and (5). ${ }^{5}$ An cflicient schedule achieves the highest possible total valuc to demanders of any feasible schedule. Define the efficiency of an allocation $X^{0}$ as:

$$
E=\frac{\sum_{i E_{i} /} \sum_{j E J} V_{i j} X_{i j}^{o}}{\bar{V}} * 100
$$

where $E$ is the efficiency and $\bar{V}$ is the optimal value.

\subsection{Parameters}

Our experiments were conducted using two sets of parameters (valuations) which differed in their level of "contention". The contention level gives us an indication as to how much conflict between users is present in the system. Our measure of contention (following Olson and Porter (1994)) is:

$$
\omega=\frac{\sum_{j} \sum_{s \in P_{j}} p_{s}}{\bar{V}}
$$

where $\bar{V}$ is the value of the objective function evaluated at the solution to the maximization problem and $p_{s}$ is the dual price of slot $s$. The levels of contention are .5 .5 and .25 for our high and low contention conditions respectively.

For our parameters, despit.e the non-convex structure of preferences, the vector of dual prices $p_{s} ; s=1, \ldots, M^{\prime} T$, (where $M^{\prime} T$ is the total number of slots) and the allocation $X^{\prime}$, where $X^{\prime}$ solves equation (6), constitutes a

\footnotetext{
${ }^{5}$ This is a form of the problem known in integer programming as the knapsack problem. The idea is to choose items to take in a knapsack when one goes on a trip. Each object has value, but it also has weight. The problem is to maximize the total value of the items taken subject to the condition that the total weight is less than or equal to some constant. This type of problem is NP-coniplete. The efficient allocation problem is more complicated, with one constraint per slot and a number of packages (objects which could be put in the knapsack) that equals $2^{\Lambda / T}-1$.
} 
competitive equilibrium. We define a competitive equilibrium as a price allocation pair $\left(X^{*}, p^{*}\right)=\left(X_{i}^{*}, \ldots, X_{i J}^{*} ; p_{i}^{*}, \ldots, p_{M T}^{*}\right)$ that satisfies the following two equations:

$$
p_{s}^{*}=0 ; \forall s \mid \exists \text { no } i, j \text { such that } s \in P_{j} \text { and } X_{i j}^{*}=1
$$

and for all $i, \exists$ no $X^{\prime \prime}$ such that:

$$
\sum_{j \mid X_{i j}^{\prime \prime}=1} V_{i j}-\sum_{j \mid Y_{i j}^{\prime \prime}=1} \sum_{s \in P_{j}} p_{s}^{*}>\sum_{j \mid X_{i j}^{*}=1} V_{i j}-\sum_{j \mid X_{i j}^{*}=1} \sum_{s \in P_{j}} p_{s}^{*}
$$

The first equation states that if a slot is not included in a package that is allocated to some demander, that its price must be zero. Since at price zero, the supplier is indil[erent to supplying or not supplying the slot, this condition insures that there is no positive excess supply of slots. The second equation indicates that each player is receiving her optimal allocation given the price vector $p^{*}$. There is no allocation that any demander would prefer at the price vector $p^{*}$ to $X^{*}$ and thus there is no excess demand at that price vector.

It can be verified from inspection of Tables 1-4, which contain the valuations and the dual prices for all packages and slots for both the High and Low contention treatments that the dual prices are indeed competitive equilibrium prices for the parameters used in the experiment.

[Table 1. about here]

[Table 2. about here]

|'Table 3. about here|

[Table 4. about here]

\section{Allocation (Scheduling) Mechanisms}

In this section we describe the gencral features of the three mechanisms whose performance we test in the environments of Section 3. The first mechanism we test is designed to capture some of the basic features of the current process 
used by JPL in the allocation of the DSN. It combines a committee process, a decision support algorithm, and a bureaucratic appeals process (see Figure 1). While we would not expect this mechanism to perform very well, we evaluate it to provide a benchmark against which to judge the performance of other mechanisms. In particular, since the research task was to find a better way to allocate shared resources like the DSN, we need to demonstrate that the new mechanisms proposed are indeed potentially better than the existing one.

We test two alternatives to the current process. First, we auction off the various slots using AUSM which was originally designed for a different allocation problem by Banks, Ledyard, and Porter (1989). It is an ascending bid auction which allows bids for packages of slots as well as for individual slots. It also has a feature called a standby queue which is designed to help bidders overcome the "threshold" problem common to these types of combinatoric problems. This mechanism is described in more detail below.

Although the AUSM with queue generally achieves high efficiencies, it also generally extracts significant surplus from the bidders. So what users have been getting inefficiently, but for free, may now be allocated efficiently but at a real monetary cost to them. The net benefit to the users, which we call users' surplus, can actually decline significantly when moving from a committee process to an auction even though efficiency improves. Proposing such a mechanism for the DSN problem is politically untenable. No mechanism which leaves current, uscrs significantly worse off will be adopted in an environment which values the users' opinions. ${ }^{6}$ To see whether we can overcome this political constraint we test a third mechanism which we call AUSM with tokens. We use the same mechanism as above but we give all users an allocation of tokens with which to bid. ${ }^{\top}$ Our conjecture was that while this mechanism might not achieve the same levels of efficiency that an auction with real monctary transfers would, it would still leave users better off because it would allow and provide incentives for users to identify tradeoffs but would not require them to pay additional lunds.

\footnotetext{
${ }^{6}$ For more on mechanisn design in which political constraints are important, see Ledyard (1993).

${ }^{7}$ This approach has sometinus been used in practice with some success (measured by users' satisfaction surveys). . Examples include scheduling business school interviews, managing computer allocations, ctc.
} 


\subsection{Negotiation (Committee Process)}

In this section we represent the process currently used in the allocation ${ }^{8}$ of DSN slots. We keep that representation in a form that can be implemented experimentally so that data on performance in a controlled setting can be acquired. The experiment is computerized, with each subject seated at his own terminal. The procedure occurs in three phases:

Phase 1: The Request Phase (See Appendix A for a numerical example.) Demanders submit requests for packages of slots of the form (n, T, Q, $\mathrm{R})$, where:

- $n \in\{1,2, \ldots, 20\}$ is the number of slots requested,

- $T \in\{$ contiguous, periodic, array, maintenance $\}$ is the type of request,

- $Q \in\{1,2\}$ is the quality of resource where $a$ is an antenna (resource) of quality $l$ and $b$ is an antenna of quality 2 , and

- $R \in\{0,1, \ldots, 9\}$ equats the range of the slots requested (the range equals the number of the rightmost column (time) in the request minus the number of the leftmost column in the request).

There is a cost to each request $C(n, T, Q, R)$ which is decreasing in the range specified (flexibility) and increasing in resource quality and the number of slots requested. The function is:

$$
\mathrm{C}(\mathrm{n}, \mathrm{T}, \mathrm{Q}, \mathrm{R})=(3-Q)(15-R)^{n} \text { francs }
$$

where francs are the experimental currency. Although there are no direct costs assessed in the current procedure at DSN, there are important opportunity costs since large and inflexible requests lead to likelihood of conflict with additional committee time required and potential for appeals to upper management. The function $\mathrm{C}$ is intended to capture these costs.

Using the requests, a two-stage algorithm creates a schedule. The algorithm we used is the actual algorithm (RALPH) used by JPL. All requests are included in the schedule. The algorithm minimizes the "average" level of contention for the resources and maximizes the "average" level of resource utilization. In the first stage it assigns fractions of each request made to every possible combination of slots which would satisfy the request. In the second stage the requests are consolidated so as to spread out the excess demand

\footnotetext{
${ }^{8}$ For a detailed description of the process tsed at JPL see Olson and Porter (1991).
} 
for slots as evenly as possible across slots. In other words, in two stages, it finds a solution to the following:

$$
\min _{X_{i j}} \sum_{s \in S}\left\{\max \left\{\sum_{i \in I} \sum_{j \in C_{m t}} X_{i j}, 1\right\}\right\}
$$

There are typically multiple solutions to cquation (11). The algorithm selects the schedule based on the order in which the scheduler inputs the requests from a mission event priority guideline provided by management. Note that multiple demanders may be assigned to the same slot. Conflicts from the multiple assignments of a slot are then negotiated in a uscr committee.

Phase 2: The Negotiation Phase Once the algorithm has operated, there follows a negotiation phase. Here demanders may freely communicate and agree to drop or swilch slots which thcy have been allocated. Although there is no direct restriction on the number of switches, all negotiations have to be completed in a predetermined time interval, which is known to all subjects. A demander's action in the negotiation phase may be either of the following:

1. A demander may agree to unilatcrally give up her assignment to a slot. This may occur in the context of a binding agreement with other subjects who also agree to give up their assignments.

2. A demander may give his currently assigned slot to another demander. This could also form a part of a larger agreement with any number of other subjects.

In our experiment, the experimenter manually alters the schedules for all subjects from his computcr terminal to reflect the agreements concluded in the negotiation phase.

Phase 3: The Appeals Phase When agrcement cannot be reached on the allocation of the schedule even after negotiation, the contending users can appeal to higher levels of management. In the experiment, any conflicts which are still unresolved after the negotiation phase are settled through an appeals process which reduces the number of demanders in any slot to one. 
We sidestep the issue of the preferences of the higher level of management by conducting the appeals process anonymously on the computer and treating all of the subjects equally during the process. To capture the idea that larger requests are more difficult to appeal, we require that a separate appeal be made for each slot. In all of our experiments the appeals process treats the appeals of all contending users equally, although this may not be the case at JPL or other organizations. During the appeals phase, subjects are required to specify for every slot, to which they and at least one other demander are assigned, whether they wish to be involved in the appeal process. There is a per slot cost to demanders who appeal, which was equal to 100 francs in the experiment, again to represent the opportunity costs involved. Each demander appealing for a slot has an equal probability of receiving the slot in the final allocation. No demander may make an appeal for a slot which is not assigned to him after Phase 2.

At the end of $P$ hase 3 an allocation is determined and subjects receive profits. Demanders' requests and appeals are unobservable to other subjects. Communication between subjects is permitted only in the negotiation phase.

\subsection{Adaptive User Selection Mechanism (Auction)}

The adaptive user selection mechanism (AUSM), is a computerized ascending price auction in which demanders enter bids for packages of slots. All slots and all packages are auctioned continuously and simultaneously. (Also see Section 3.) A demander can enter an integer bid for any package. Let $b_{i j}>0$ denote a bid by demander $i$ for package $j$. The process can be most easily understood using the concept of a standing bid. Let $S_{j}$ be the standing bid for package $j$. At any time the collection of packages for which there is a standing bid will constitute a feasible allocation. A new bid, $b_{i j}^{\prime}$, can become a standing bid if it is greater than the sum of all standing bids for all packages which contain slots which intersect with package $j$. In other words $b_{i j}^{\prime}$ is accepted and becomes a new standing bid $s_{j}$ when:

$$
b_{i j}^{\prime}>\sum_{k i P_{k} \cap P_{j} \neq \emptyset} S_{k}
$$

The previous standing bids $S_{k}$, where $k$ is as defined in equation (12), are then displaced and are no longer considered standing bids. An important 
feature of this process is that the sum of all standing bids can only increase when a new bid is accepted. ${ }^{9}$ When the auction closes, the demander in possession of the current standing bid for package $j$ receives that package.

The auction was closed manually by the experimenter at random within a time interval known to subjects, although the exact time of closing was not known to them in advance. The auction was open for 6-8 minutes in the early periods of each experiment and 4-6 minutes in the late periods. The random ending was designed to prevent a sudden surge of bidding activity at the end of the market period which would occur if the exact time of closing were known to bidders. ${ }^{10}$ Also, if at any time, no new bid was received for a 20 second time interval, the market was closed by the experimenter.

This mechanism as it stands has an undesirable feature that may lead to inefficient outcomes, because larger users can prevent smaller but highervalued users from winning. Suppose, for example, that demander 1 has a valuation of 3000 rancs for a package consisting of items 1a, 2a, and 3a, demander 2 has a valuation of 2000 francs for item 1a, and demander 3 has a valuation of 2000 for a package consisting of items $2 a$ and $3 a$. In the highestvalued allocation, demander 2 receives item $1 \mathrm{a}$ and demander 3 receive $2 \mathrm{a}$ and 3a. However, if demander 1 hids 2001 francs for the package of 1a, 2a, and $3 \mathrm{a}$, then neither demander 2 nor demander 3 can unilaterally displace 1's standing bid without bidding more than his individual value. Thus, the mechanism produces an inefficient outcomes.

To overcome this threshold coordination problem, a feature called Standby Queue for Unifying Individual Demanders (SQUID) was added to the Adaptive User Selection Mechanism. ${ }^{11}$ This queue allows individual demanders to jointly submit bids in order to displace standing bids for large packages. A public bulletin board is provided for bidders where they can place a bid that they would be willing to have win but which is not sufficiently large to become a standing bid by itself. In the above example, a bid to pay

\footnotetext{
${ }^{9}$ It is, of coursc, possible for the standing bids of any particular package to fluctuate over time.

${ }^{10}$ The experinenter drew closing times before the periods started using a random number generator. This allowed the experimenter to be sure that he was unaffected by the market activity during the period when deciding when to close the market.

${ }^{11}$ The idea is to provide a forum for communication since experimental evidence suggests that the best way to overcone the threshold problem is to allow subjects to communicate. See Ledyard (1991) for a survey of some of these experiments.
} 
1300 for slot la by demander 2 would be such a bid. Once placed on the standby queue, that bid can be used by others in concert with their own bid to displace a large bid such as the bid of 2001 for the package of slots 1a, $2 \mathrm{a}$ and $3 \mathrm{a}$ by demander 1 . In the example, once demander 2 has placed a bid in the queue, demander 3 can then choose to combine a bid of his own with demander 2's offer on the standby queue. He might then bid 702 francs for slots $2 a$ and $3 a$ in combination with 2's offer of 1300 for .1a. Since they jointly have a sufficiently high bid to displace demander 1's bid they can do so. Demander 3 can unilaterally execute the joint bid and 2's component is binding on 2 once it is executed. Prior to execution, bids can be withdrawn from the standby queue. Any number of bids could be combined to form one joint bid, with the limitation that each bidder could have at most two bids on the standby queue at any time. Bids cannot be withdrawn when they are a standing bid.

\subsection{AUSM with Tokens}

The AUSM mechanism with the standby queue was also implemented as a mechanism where bids wcre made, not in terms of an experimental currency convertible to U.S. dollars, but rather using tokens which had no value to demanders and which served only as a medium of exchange. Each demander received a budget of tokens at the beginning of each period with which to bid. Any tokens remaining at the end of the period had no value to the demander and were forfeited before the start of the next period.

Since the initial distribution of tokens is an important aspect in the design of any bidding mechanism which uses tokens, we included two subconditions in the research design, which differed only in the amount of tokens with which subjects were endowed at the beginning of each period. In the Equal Endowment condition, each subject received an equal endowment of tokens each period. In the Competitive Endowment condition, the endowment of tokens available to each subject was proportional to the minimum number of francs required by each subject to achieve the competitive equilibrium allocation. ${ }^{12}$ In each of the four experimental sessions of AUSM/tokens, each endowment was used for at least three market periods. Subjects were always informed if the endowments were going to change in the next period. Subjects knew

\footnotetext{
${ }^{12}$ If the minimum was less than if francs, the ericlowment given was raised to 5 francs.
} 
their own endowment but not the endowment of other demanders. Subjects also knew that there were only two possible initial distributions. The initial allocations of tokens to subjects are given in Table 5.

[Table 5 about here]

Although some of the demanders in the Competitive Endowment condition (demander 5 in low contention and demander 6 in high contention) received endowments much lower than other demanders, they were nevertheless usually able to purchase units, since there existed packages for which only they had a positive valuation.

\subsection{Sequential Random Efficiency}

One metric by which to evaluate the performance of a mechanism in a particular environment is to compare the efficiency achieved to that generated by a naive computer algorithm. This protects against claims of superior performance by a mechanism when it is really only an "easy" environment which allows high efficiencies. The algorithm we have chosen is a generalization of the sequential dictator algorithm analyzed in Olson and Porter (1994). The algorithm consists of the following steps.

1. Pick a user. Each user is picked with equal probability.

2. Allocate to that user his most valuable package which is feasible. A package is feasible if no subset of it has been allocated to any other demander.

3. Go to 1. if there exist slots which have not been allocated.

4. Compute $\sum_{i} \sum_{j} V_{i j} X_{i j}$ for that allocation, divide by $\bar{V}$, multiply by 100 .

The algorithm was run 10000 times for each set of parameters. The results of the first 2500 runs are depicted in Figures 4 and 5 . The algorithm generates an average efficiency of 89.79 and 82.61 for the low and high contention conditions respectively, with standard deviations of 9.02 and 8.76 . The algorithm results in the optimal allocation 28.94 and 2.25 percent of the 
time in the low and high contention conditions, respectively. ${ }^{13}$

[Figure 4. about here]

[Figure 5. about here]

\section{Results}

All of the 12 experiments were conducted in April 1993 at the Laboratory for Experimental Economics and Political Science at the California Institute of Technology. Each experiment consisted of between 8 and 12 market periods. All subjects were undergraduates or pre-freshmen at the Institute. In the following table, we display' some design information concerning the experiments:

[Table 6. about here]

In the rows corresponding to AUSM/tokens in the column labelled Num. Periods, the two numbers in parentheses represent the number of periods in the session where the Equal and the Competitive endowment conditions respectively were in effect. The instructions used in the experiments can be found in Appendix B.

\subsection{The Data}

Our analysis of the effects on allocative efficiency and the cost to users of varying the level of contention and of replication of the market conditions is based on the estimation of regression equations. The following equations were estimated using the data from the committee and the AUSM/money processes:

$$
y_{i}=\beta_{0}+\beta_{1} \text { period }+\beta_{2} \text { hicon }+\epsilon \quad i=1,2
$$

$y_{1}=$ efficiency (as defined in equation 4 ) and $y_{2}=$ cost to users. Users' surplus can then be computed as $y_{1}-y_{2}$. The cost to users is the percentage of $\bar{V}$

\footnotetext{
${ }^{13}$ The algorithm generates, on average, higher efficiencies under low contention for our parameters, although, in general, higher contention does not always imply lower average efficiency.
} 
paid out by subjects during the market period. In the committee process it is equal to the request costs plus the appeals costs. For the AUSM/money the cost to users is equal to the amount of cash paid out by subjects to obtain their allocation. There are no costs to subjects in the AUSM/tokens.

The variable period is equal to the number of market periods that have elapsed in the experimental session including the current period. It can be interpreted as a variable which isolates the effect of the learning or experience of subjects on the value of the dependent variable. The dummy variable hicon takes on a value of 1 in the high contention treatments and a value of 0 in the low contention treatments and therefore identifies the effect of variations in the contention level.

The following equation was estimated for the AUSM/tokens data:

$$
e=\beta_{0}+\beta_{1} \text { period }+\beta_{2} \text { hicon }+\beta_{3} \text { compendow }
$$

where $\mathrm{e}=$ efficiency and compendow=1 if the Competitive Endowment condition is in effect and equals 0 otherwise. For the AUSM/tokens data, since all rents go to the demanders, market efficiency is exactly equal to users' surplus. The variable compendow identifies the effect on efficiency of varying the initial endowment of tokens. The results of the estimations of the five equations are given in the following table. The standard errors of the estimates are given in parentheses.

[Table 7. about here.]

Tables 8-10 contain the estimated efficiency and the estimated cost to users of each of the three allocation mechanisms in periods 1 and 10, as well as under the two contention levels. The numbers in tables 8-10 are taken from the estimated coefficients in Table 7. L and $H$ represent the Low and High contention treatments respectively. L1 and L10 denote the estimated value of the relevant variable in periods 1 and 10 respectively in the low contention condition. The estimates in tables 8-10 are the values of the regression in the relevant period and treatment, and not the actual observed values of the variables. Thus, it is possible, as in the low contention period 10 estimate of the cost in the committee process, that the estimated value could be negative although the actual costs must always be greater than or equal to zero. The figures in parentheses give the probability that the efficiency or the users' surplus from the sequential dictator algorithm is less 
than or equal to the estimated surplus from the mechanism. So low numbers in parentheses indicate poor performance by the mechanism relative to the sequential dictator (random) algorithm.

['Table 8. about here]

The efficiency generated by the committee process at the beginning of the experimental sessions is less than that generated by the random algorithm in both the high and the low contention environments. In the low contention condition, however, the efficiency of the committee process improves over time so that, on average, it is better than the random algorithm by period 10. However, in the high contention environment, the committee performs very poorly and, even by period 10, does not achieve efficiencies as high as the random algorithm.

The costs to users in the committee process decline with time as users apparently learn to avoid these bureaucratic frictions. Higher contention makes such avoidance more difficult. The most remarkable finding is that only in a low contention environment, and only after a number of replications does the current committee process, with a decision support algorithm, outperform the simple sequential dictator algorithm.

[Table 9. about here)

From an efficiency point of view, AUSM/money performs better than the committee in both the high and the low contention conditions. The efficiency is also increasing over time. By the tenth period, AUSM significantly outperforms both the committee process and the sequential dictator algorithm. However, increases in efliciency are associated with increasing costs to the users so that user surplus remains unchanged. In fact, users' surplus is substantially less under AUSM than under the committee process or under the random algorithm described in section 5.4.

[Table 10. about here]

Under the AUSM/tokens, efliciency and, thus, users' surplus increases over time. The efliciency is higher under high than under low contention. Under high contention, the users' surplus was largest under the AUSM/tokens mechanism than any of the three others. . Furthermore, as can be seen in Table 7, changing the token endowment had no effect on the efficiency levels recorded. This is somewhat unexpected so it is reasonable to consider fur- 
ther the distributional effects of the different token endowments. A natural measure of this effect is the sample variance of payoffs among the users which can be defined as:

$$
S^{2}=\sum_{i=1}^{l} \frac{\left(\pi_{i}-\bar{\pi}\right)^{2}}{I-1}
$$

where, $S^{2}$ is the sample variancc, $\pi_{i}$ is the profit of demander $i$, which equals the sum of his valuations (in terms of (rancs) for the packages he receives and $\bar{\pi}$ is the average profit of demanders. The variance is analysed by estimating the equation below. The estimates are reported in Table 11:

$$
S^{2}=\beta_{0}+\beta_{1} \text { period }+\beta_{2} \text { hicon }+\beta_{3} \text { compendow }
$$

[Table 11. about here]

One can see in Tialsle 11 that the change in endowment also has no significant effect on the variance of the payoffs. The fact that the variances are not different, however, does not suggest that there were no distributional differences under the two endowments. For example, under low contention, demanders 3 and 4 were substantially worse off (payoffs were 15 and 19 percent lower respectively), while demander 6 was better off (by 19 percent) in the Equal Endowment condition than than in the Competitive Endowment condition. Under high contention, demander 4 received considerably higher payoffs (by 30 percent) in the Competitive Endowment condition while demander 6 reccived considerably lower payoffs (by 37 percent). The two following tables show the percentage of market periods in both subconditions in which each demander received each of the packages which had value to him. The columns labelled EE and CE indicate the percentage of the time that package $P_{j}$ was allocated to demander $i$ under the Equal Endowment and Competitive Endowment treatments respectively.

[Table 12. about here]

|'Table 13. about here|

Under both endowments and both levels of contention, each package except for package $(1 \mathrm{~b} ; 6 \mathrm{~b})$ under low contention in the Equal Endowment condition, was allocated efficiently (that is to the correct demander) at least 
50 percent of the time. This suggests that efficiencies under both endowments are high and not much different from each other. Under both sets of endowments of tokens, the demanders with the highest valuations were generally able to bid high enough to price out competing demanders. Even the very small endowments of demander 5 under low contention and demander 6 under high contention were enough to allow the user to purchase the packages which they would receive in the competitive equilibrium, because there were no compcting demanders for these packages.

Under high contention, demanders 1, 2 and 5, who were in the same viewperiod, usually received the same allocations across the two endowments. Demanders 3 and 4 , who were in the same viewperiod as demander 6 , sometimes purchased packiages meant for each other. Demander 4 had a much larger endowment of tokens in the Competitive Endowment condition than demander 3 who in turn had a much larger endowment than demander 6 . Not surprisingly, 4 received packages $(1 \mathrm{~b}, 6 \mathrm{~b}),(2 \mathrm{a}, 7 \mathrm{a})$ and $(2 \mathrm{~b}, 7 \mathrm{~b})$ more often in the Competitive Endowment condition when he had a larger endowment. The maintanance demander 6 , received the same packages less of ten when she had the smaller endowment. 3 was able to purchase $(1 \mathrm{~b}, 6 \mathrm{~b})$ more of ten in the Competitive Endowment condition, easily outbidding demander 6, who was never able to purchase ( $1 \mathrm{~b}, 6 \mathrm{~b}$ ) in the Competitive Endowment condition but was able to purchase it 36 percent of the time in the Equal Endowment condition. The average allocative efficiency under the two endowments was 93.7 and 95.3 for the Equal and Competitive endowments respectively.

A similar pattern occured under low contention. The contiguous demanders 1 and 2 usually divided packages $(9 a, 10 a)$ and $(9 b, 10 b)$ between them. Demanders 3 and 4 often received packages intended for the other, with 4 receiving more packages under the Competitive Endowment condition, when his token endowment was greater, usually at the expense of demander 6 . Demander 5, with his very low endowment in the Competitive treatment, was able t,o obliatin his most. preferred package, but his budget was too low to obtain the other package. Demander 6 was substantially worse off in the Competitive Endowment condition since she was less able to compete in the bidding with demanders 3 and 4 . 3 was sometimes able to get the package consisting of $(1 \mathrm{a}, 6 \mathrm{a})$ and 4 received $(3 \mathrm{a}, 8 \mathrm{a})$ and $(\mathrm{b}, 6 \mathrm{~b})$ more often. Efficiency was on average 87.0 and 90.2 in the Equal and Competitive Endowment treatments respectively. 


\subsection{Discussion}

Under low contention, the Committee process provides more surplus to users as a whole than the AUSM/tokens which in turn provides more users' surplus than AUSM/money. 'This is consistent with the field observation that there is of ten little effort to replace committees with market-type systems of allocation when conflict between users is not too severe even though efficiency may be low. The committee process gives users more surplus than the two other mechanisms even though it does no better than the sequential dictator algorithm. Under high contention, however, AUSM/tokens yields the highest surplus to the users, followed in order by the sequential dictator algorithm, the committee and AUSM/money. The committee clearly fails when the level of contention increases since the cost of negotiation and conflict resolution increases and the ability of the mechanism to allocate the schedule efficiently diminishes. AUSM/tokens behaves in the opposite way. The user surplus is higher when contention is high, since the efficiency is higher and user costs are zero. Under both high and low contention, the AUSM/money, with its extraction of rents from the users, generates lower users' surplus than the other mechanisms. When highly efficient auctions such as AUSM are proposed by economists to solve allocation problems, we should expect such recommendations to encounter resistance from thoughtful future bidders in the auction.

The relatively strong performance of the sequential dictator algorithm is not surprising. The sequential dictiator algorithm has aspects which give it a good chance to enhance efficiency. One is the fact that it sidesteps the information revelation problem, by choosing for each subject his most preferred package. ${ }^{14}$ Our implementation thus assumed perfect information but the resulting allocations were compared against those generated by the interaction of strategic agents in an incomplete information environment. The efficiency of the sequential dictator as we have measured it should therefore only be treated as a benchmark and this paper should not be considered a test of its performance as a mechanism.

From the standpoint of system efficiency, some of the mechanisms are superior to others. Under low conlention, AUSM/money, the committee and

\footnotetext{
${ }^{14}$ In the one-to-one ussignment problem; such honest revelation is a dominant strategy. (See Olson (1993) and Olson and Portor (1991)). This is no longer true in this fundamentally more complex many to one environment.
} 
the sequential dictator algorithm perform better than AUSM/tokens. Under high contention AUSM/money and AUSM/tokens generate more efficient allocations than the random algorithm, which in turn had more efficient outcomes than the committee. This reinforces the findings of Banks et al. (1989) that the AUSM is capable of generating very high allocative efficiencies in complex non-convex environments.

There is evidence of improvement over time in the level of efficiency in all three of the mechanisms. The estimated efficiency level is higher in period ten than in period one in all six conditions. Cost declined in the committee as users seemed to learn to avoid conflicts over time. In AUSM/money, the revenue extracted from the users increased with replication of the auction, and rising revenue seemed to be related to increasing efficiency.

Although varying the distribution of tokens in AUSM/tokens had no effect on total payoffs or on the variance of payoffs for the particular parameters of our experiment, the distributions of payoffs across subjects was different, as demanders with lower endowments received lower payoffs. The robustness of this market efficiency finding should be interpreted with caution and does not suggest that the initial distribution of tokens can be ignored by planners in field applications. The result does suggest, however, that there is some room for flexibility in varying the initial distribution of tokens, without causing large fluctuations in allocative efficiency.

\section{What Have We Learned ?}

At the beginning of this paper we presented a stylized story to illustrate why user committees might be able to survive as organizational devices to manage shared facilities even though it is widely recognized by both the users and the organization that significant value is being foregone. Our study provides new evidence supporting the foundations of this pessimistic view. However, our study, using the methodology of applied mechanism design, also establishes that there are viable alternatives to user committees that do not involve large losses in value to the users. This provides some evidence that significant increases in value, for both users and the organization, can be found and captured by using designed mechanisms to improve the management of shared facilities.

The basis for these somewhat sweeping statements can be found in three 
key findings of our study. We split the first finding focusing on the performance of user committees into two parts. (1a) Experienced user committees using decision support algorithms produce reasonably efficient allocations in lower conflict situations. The key facts supporting this observation are found in Table 8. By period 10 in the low contention environment, the user committees are achieving, on average, $96 \%$ of the maximum value with virtually no cost to the users. The probability that the user committee yields a higher value than the random algorithm is, however, only $71 \%$, which may not be good but good enough to support the continued use of the committee. (1b) Experienced user committees using decision support algorithms produce reasonably bad allocations in high conflict situations. The key facts supporting this observation are also found in Table 8. By period 10 in the high contention environment the user committees are achieving on average, $77 \%$ of the maximum value with a cost to users of $5 \%$ of the maximum value. The basis for describing this performance as bad is that the probability that the user committee yields a higher value than the random algorithm is only $10 \%$ in the high contention environment. There is obviously significant value being foregone.

The second key finding concerns the viability of an "economic" solution for the recovery of the value foregone. We also split this into two parts. (2a) There is an economic process, called the Adaptive User Selection Mechanism (AUSM), in which users bid and pay dollars for time, which yields high efficiencies in high-conflict situations. The key facts supporting this observation are found in Table 9. In the very first period and in the high contention environment, AUSM/Money is achieving $86 \%$ of the maximum possible value. By period 10 in the high contention environment it is achieving, on average, $96 \%$ of the maximum possible value. The basis for calling this high is that the probability that the random algorithm would do better is only $5 \%$. There is obviously significant value being created by this economic solution - about a $25 \%$ increase in value over the user committee and, using a better measure of improvement, a $365 \%$ increase in the probability of beating the random algorithm. (2b) Because of the prices paid, the economic solution of AUSM/Money leaves users significantly worse off than user committees do. The key facts supporting this observation are found in Tables 8 and 9. Looking at period 10 in the high contention environment, we see that the user committee leaves a users' surplus of $72 \%$ whereas, because of the payment of fees, AUSM leaves the users a surplus of only $43 \%$. Neither is particu- 
larly desirable, since it is essentially a sure thing (almost a $100 \%$ probability) that the random algorithm would yield a higher surplus than AUSM. There should remain little mystery as to why user committees don't like market solutions especially in those high contention situations where they are most of ten espoused.

The third key finding concerns the existence of better mechanisms for both the users and the organization. (3) There is a modification of AUSM in which tokens, or internal money, replace real money and which results in highly efficient allocations without extracting any of the users' surplus. The key facts supporting this observation are found in Table 10. By period 10 in the high contention condition, with an equal allocation of tokens AUSM/Tokens is producing on average efficiency and users' surplus equal to $97 \%$ of the maximum possible. This is very high in the sense that there is only a $5 \%$ chance that the random allocation would produce a higher value. (A surprising and unexplained fact is that this is as high a gross value on average as AUSM/Money achieves.)

We conclude with several policy thoughts. From the point of view of a planner interested in achieving a high allocative efficiency, AUSM is clearly the best of the mechanisms considered here. The efficiencies generated by AUSM are, in our view, very high considering the complex combinatorics required by the non-convexities in the preference structure of the environment. We are doubtful that other mechanisms could do better although it surely remains an open research challenge to find a better one.

From the point of view overall users' surplus, mechanisms can be found which surpass AUSM/money. When contention is low, it seems to be difficult to improve upon the current committee process. None of our alternative mechanisms were able to. This may be why extensive conflict is necessary before users are willing to discard committee systems. When contention is high we find that AUSM/Tokens generates very high surpluses for the users. The tokens seem to provide enough information to coordinate the allocation of slots efficiently, yet the buyers do not have to give up any surplus. This effect was surprisingly robust to changes in the initial endowment of tokens.

When conflict is high, it will be revealed in complaints about the current committee/negotiation process. Under these circumstances, using a carefully designed auction with tokens may appeal to the users in a way that an auction using real money would not. The remaining hinderance to the adoption of AUSM/tokens is the fact that the initial endowment of tokens must be 
determined. In the experiments reported in this paper, some demanders were considerably better off under one or the other allocations of token endowments. Since this is likely to be the case anywhere in the field, and since users are likely to know this. it can impede a transition from committees to better designed mechanisms unless one can find an appropriate grandfathering procedure. This is the subject of future economic design research. 


\section{A An Example of Phase 1 of the Committee Process}

Suppose that there is one resource $(M=1)$, and there are three times $(T=3)$, so that there are a total of three slots. For this example denote the three slots as slots 1,2 and 3 , according to time. The resource is of quality 1 , and there are two users, each of whom makes one request. User 1's request is (2,C,1,13 ), that is (2 slots, at adjacent times, on a quality 1 resource, anywhere between columns 1 and 3$)$, and user 2 's request is $(1, M, 1,1-3)$. The request costs are therefore $(3-1)(15-2)^{2}=338$ and $(3-1)(15-2)=26$ respectively.

There are two possible packages which satisfy request 1 and three which satisfy request 2. The first stage of phase 1 results in the following provisional allocation:

For user 1's request: .5 weight on the package consisting of slots 1 and 2 and .5 weight on the package consisting of slots 2 and 3 .

For user 2's request, $1 / 3$ weight on each of the three possible single slot packages, consisting of one of a1, a2 and a 3 respectively.

In the second stage of phase 1 . the stage 1 allocations are consolidated to one of two possible assignments. which are:

1) User 1 is assigned slots 1 and 2, user 2 is assigned slot 3 .

2) User 2 is assigned slots 2 and 3, user 2 is assigned slot 1 .

\section{B Instructions Read to Subjects}

The following pages contain the instructions which were read aloud to subjects at the beginning of each experimental session. 


\section{INSTRUCTIONS}

\section{GENERAL}

You are about to participate in an experiment in which you will make decisions in a market. If you follow the instructions carefully, you might earn a considerable amount of money which will be paid to you in cash. For this experiment all transactions will be in terms of francs. You can convert your franc earnings into U.S. dollars at a rate of _-__- francs to 1 U.S. dollar. You will be paid at the end of the experiment.

The experiment will be broken-up into a series of periods in which you will make decisions. Each period you will be given a Redemption Value Sheet which describe the value to you of decisions you might make. You are not to reveal this information to anyone. A Redemption Value Sheet lists packages of items and the value in francs to you of that package of items. Below you will find an example Redemption Value Sheet with three packages.

REDEMPTION VALUE SHEET

\begin{tabular}{|c|c|c|c|c|c|}
\hline \multicolumn{5}{|c|}{ Package } & Value \\
\hline Item & Item & Item & Item & Item & \\
\hline $7 \mathrm{a}$ & $8 \mathrm{~b}$ & $9 \mathrm{~b}$ & & & 2000 \\
\hline $7 \mathrm{a}$ & $8 \mathrm{~b}$ & & & & 800 \\
\hline $5 \mathrm{~b}$ & & & & & 500 \\
\hline & & & & & \\
\hline & & & & & \\
\hline
\end{tabular}

A package is defined as a set of up to 4 items. An item, which will be described in more detail later, is simply a unique number and letter identification. Associated with each package is the value to you in francs, of obtaining the items in the package. For example, in the sheet above the package consisting of items $7 \mathrm{a}, 8 \mathrm{~b}$ and $9 \mathrm{~b}$ has a value of 2000 francs. However, if you were to only obtain items $7 \mathrm{a}$ and $\mathbf{8 b}$ you would only receive 800 francs. You can obtain items to make packages through a process we will describe later. Your earnings for a period are the sum of the values of the packages you have at the end of the period minus vour cost in obtaining the packages.

Some clarifications:

- Only packages you have in your possession at the end of a period count toward your earnings. Costs are given as the sum of the costs you have incurred over 
the period.

- An item can be used in one and only one package at the end of a period.

\section{ITEMS TO BE ALLOCATED}

You are one of _-_ participants in our experiment. Information concerning the allocation of items and your specific allocation of items will be displayed to you through your computer terminal. For the experiment you be given an ID number which is displayed in the upper left-hand corner of your screen.

You can find a display of all of the items to be allocated by pressing D. An item is determined by a row and a column. There are a total of 60 items arranged in four resource rows ( $\mathrm{a}, \mathrm{b}, \mathrm{c}$ and $\mathrm{d}$ ) of fifteen column positions each. In the figure below titled Subject Detail Screen the items are displayed (you will only be able to see five positions at a time on your computer screen. You can use your arrow keys to move around and see the rest of the display). An $\mathrm{X}$ in a resource position means the item will never be part of a package which has value to you and therefore it is not usable to you. There are two possible configuration of usable items to participants (Configuration $A$ and $B$ ). There are four participants possessing each configuration. If you currently have an item your ID number will be placed in the upper portion of a bighlighted resource position box. For example, in the figure below participant 2 currently has items 22 and b4.

SUBJECT DETAIL SCREEN

a

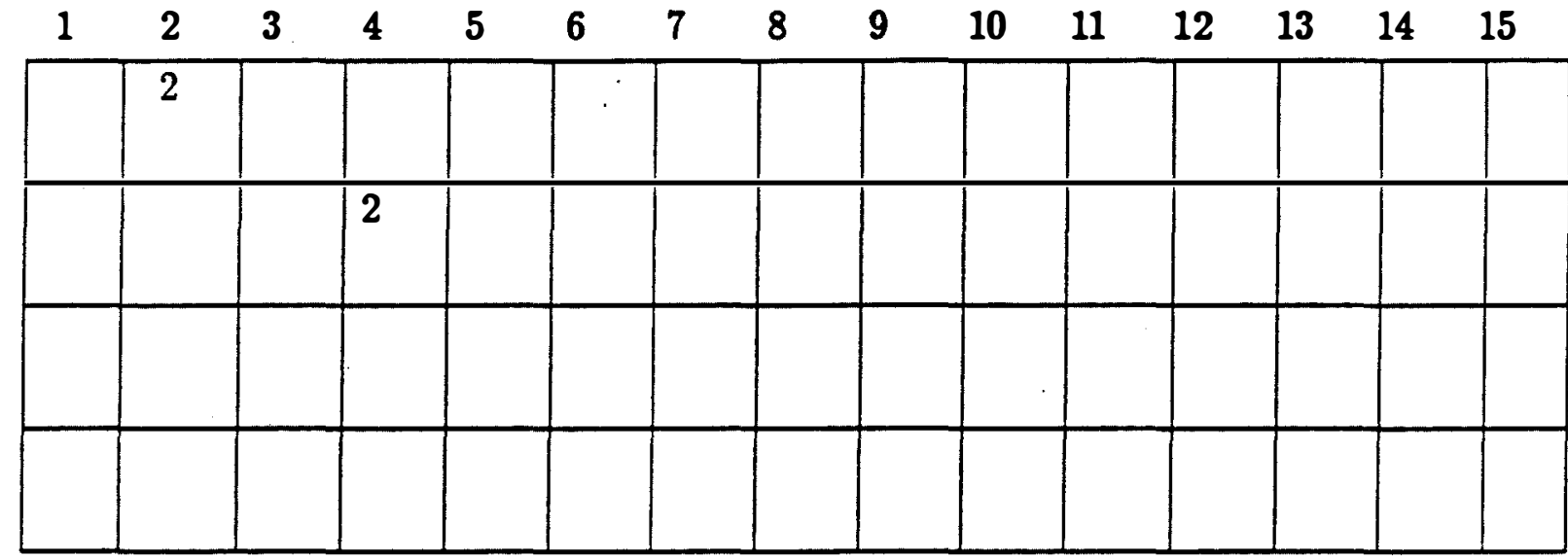

In summary, the items available for allocation are specified by:

- A resource (a, b, c or d) and a position (1-15). Thus item a7 is defined as resource a in position 7.

- The set of usable items to a participant is given by an items Configuration of $A$ or B. 
- The current allocation is given in the subject detail screen listing participant IDs in resource position boxes.

\section{PARTICIPANT TYPES}

In each market period, participants will be assigned to one of four different types. Your type for a period, which can be found in the upper right hand corner of your period Redemption Value Sheet, can be either:

- Contiguous types which value packages that are adjacent to one another on the same resource. For example, in the figure below, participant 1 has a potential contiguous package composed of $3 a, 4 a$ and $5 a$.

- Periodic types only value packages that contain items that are spaced five positions apart on the same resource. An example of this type of package is given in the figure by participant 3's potential package of $1 \mathbf{a}$ and $6 \mathrm{a}$.

- Array types value packages that use resources $a$ and $b$ in the same positions. An example of this is participant 4's potential package of $7 \mathrm{a}$ and $7 \mathrm{~b}$.

- Maintenance types value any single position resource that is usable. Two examples are participant 6's potential packages of $2 \mathrm{~b}$ or $10 \mathrm{~b}$.

SUBJECT DETAIL SCREEN

SUMMARY:

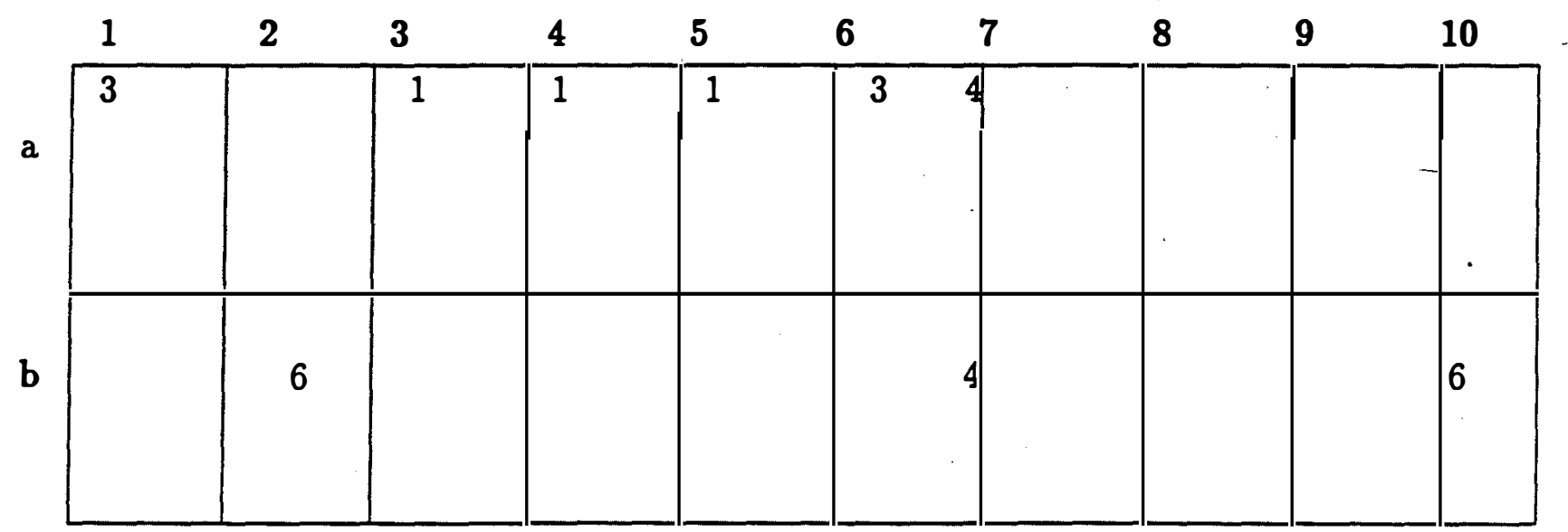

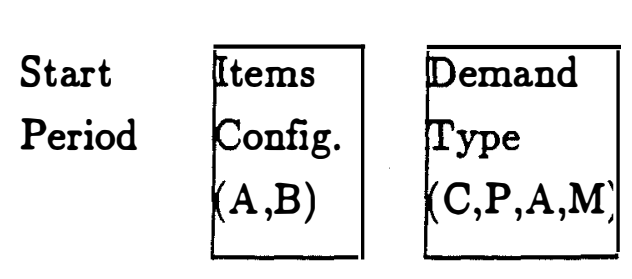

\begin{tabular}{|l|}
\hline Package \\
Values \\
Redemp. \\
Value \\
Sheet) \\
\hline
\end{tabular}

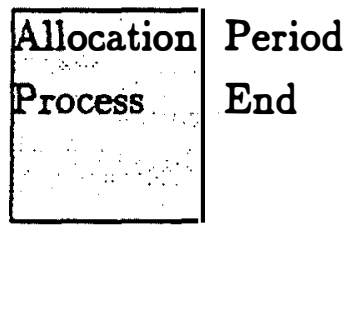

Packages 
IV. THE ALLOCATION PROCESS

At the beginning of each period, you will be able to submit a request for packages to be scheduled in the sixty possible resource position boxes. To submit a request for packages just press $\mathrm{R}$ to get your request form. A screen resembling th? one below should appear.

Request Screen

\begin{tabular}{|l|l|l|l|l|l|l|}
\hline Ant & Unit & Type & Begin & End & Period & \\
\hline & & & & & & \\
\hline & & & & & & \\
\hline & & & & & & \\
\hline & & & & & & \\
\hline & & & & & & \\
\hline
\end{tabular}

A single request for a package consists of a filled out row in the request form. The request is composed of:

(i) Ant defines the resource row you would like, the possibilites are: $\mathbf{a}$ or $\mathbf{b}$

(ii) Unit describes the number of columns of the resource you want.

(iii) Type describes how you want your package designed, the possibilities are:

$C$ for contiguous, $A$ for array, $P$ for periodic, and $M$ for maintenance

(iv) Begin corresponds to the minimum column number to start the package at.

(v) End corresponds to the maximum column number to end the package on.

(vi) Period describes the number of columns to separate the units by. It is only used with requests of type $P$.

\section{EXAMPLE:}

Suppose you want to request the following three packages:

(1) a6.

(2) Three contiguous columns on a.

(3) Any 2 columns on resource b anywhere from column 4 to column 10.

These three requests are filled-in the the form below: 


\begin{tabular}{|l|l|l|l|l|l|l|}
\hline Ant & Unit & Type & Begin & End & Period & \\
\hline $\mathrm{a}$ & 1 & $\mathrm{M}$ & 6 & 6 & & \\
\hline $\mathrm{a}$ & 3 & $\mathrm{C}$ & 1 & 10 & & \\
\hline $\mathrm{b}$ & 2 & $\mathrm{M}$ & 4 & 10 & & \\
\hline & & & & & & \\
\hline & & & & & & \\
\hline
\end{tabular}

Once you have typed in all the of requests you would like have scheduled for the period press $<E s c>$ and then $Y$ to confirm your requests. You can send in only one request form per period. Each request in the request form that you send to the scheduler has a cost associated with it. The cost of a request is given by the following schedule:

$$
\text { Request Cost Schedule }
$$

Ant $=\mathbf{a}$

Units

Requested

End minus Begin

\begin{tabular}{|c|c|c|c|c|c|c|c|c|c|c|c|c|c|c|c||}
\hline & 0 & 1 & 2 & 3 & 4 & 5 & 6 & 7 & 8 & 9 & 10 & 11 & 12 & 13 & 14 \\
\hline 1 & 30 & 28 & 26 & 24 & 22 & 20 & 18 & 16 & 14 & 12 & 10 & 8 & 6 & 4 & 2 \\
\hline 2 & 60 & 56 & 52 & 48 & 44 & 40 & 36 & 32 & 28 & 24 & 20 & 16 & 12 & 8 & 4 \\
\hline 3 & 135 & 126 & 117 & 108 & 99 & 90 & 81 & 72 & 63 & 54 & 45 & 36 & 27 & 18 & 9 \\
\hline 4 & 240 & 224 & 208 & 192 & 176 & 160 & 144 & 128 & 112 & 96 & 80 & 64 & 48 & 32 & 16 \\
\hline
\end{tabular}

Ant $=\mathrm{b}$

Notice that the cost per request is higher for requests that require resources a or $c$, is increasing in the number of units requested and decreasing in the range over which request can be scheduled.

Once all requests have been sent an initial schedule is constructed by the scheduling algorithm. The algorithm attempts to minimize average contention over the resource positions and never schedules a request that is not in your veiwperiod. Contention occurs when a resource position is assigned to more than one participant. In general, if you want to reduce the probability of contention for a request you submit:

- Request less units and/or allow for a large end minus beginning 
After a schedule is calculated, it will be displayed on your screen in the subject detail screen. The resource positions that have been scheduled to you are highlighted along with a list of all participants who have also been assigned the same resource position. If there is contention over resource positions, a negotiation phase will be conducted in which you can communicate with the other participants. The monitor will ask if any participant wishes to trade or withdraw from resource positions. You may then withdraw or trade positions you have been scheduled. If some parties come to an agreement the experimenter will edit the schedule to reflect the change.

If contention still exists after the negotiation phase has ended, then an appeal process will begin. When the appeal phase begins an appeal screen will appear on your terminal. Your appeal screen will list all those resource positions at which you are still in contention. You must indicate your desire to appeal for the position by placing a $Y$ for yes and an $\mathrm{N}$ for no, for each position that appeal. It will cost you 100 francs for each position which you appeal for whether or not you receive the position after the appeal. Each participant that appeals for a position has an equal chance of being assigned the position. For example, if three participants are contending for resource position $7 \mathrm{a}$ and each participant appeals for the position, each has a one-third chance of receiving it. If you do not appeal for a position for which there is contention you will not be assigned that position.

At the end of each period the program will calculate your request costs, appeal costs, and redemption values for you. Nonetheless, you should maintain your own accounting records by using the accounting form in your packet. Your earnings for the period are the redemption values of the resource positions assigned to you in the final schedule minus your request and appeal costs. 


\section{The Allocation Process}

\subsection{The Auction}

The allocation process consists of an ascending price auction. You bid for packages of items. You must bid higher than the current standing bid for the package to have your bid accepted. The market will remain open for 6 to 8 minutes. If you have the current standing bid for a package when the market closes, you receive the package.

\subsection{The Standby Queue}

The auction will include a feature called a standby queue. You may combine your bids with the bids of other market participants to displace a current standing bid by using the standby queue.

For example, suppose that:

Person 1 has a current standing bid of 100 francs for items a1 and a2.

Person 2 can place an offer on the standby queue of 60 francs for item a1.

Person 3 may then combine with person 2 by making an offer of 50 francs for a2. Then, persons 2 and 3 jointly displace person 1 . Person 2 now has a standing bid of 60 for item a1. Person 3 has a standing bid of 50 for item a2. 


\subsection{Your Screen}

On your computer screen, you can see four windows like the following:

\begin{tabular}{|c|c|c|}
\hline Standby & Bid & Package \# \\
\hline Y & 100 & 7 \\
\hline
\end{tabular}

\begin{tabular}{|c|c|c|c|}
\hline$\#$ & Package & Status & $\$$ \\
\hline 1 & $\mathrm{a} 8, \mathrm{a} 9, \mathrm{a} 10$ & Accepted & 200 \\
\hline 2 & $\mathrm{~b} 8, \mathrm{~b} 9, \mathrm{~b} 10$ & Bumped & 30 \\
\hline & & & \\
\hline & & & \\
\hline & & & \\
\hline & & & \\
\hline & & & \\
\hline & & & \\
\hline
\end{tabular}

\begin{tabular}{|c|c|c|c|}
\hline$\#$ & Package & Subject & $\$$ \\
\hline 1 & $\mathrm{a} 3$ & 2 & 50 \\
\hline 2 & & & \\
\hline 3 & $\mathrm{~b} 4, \mathrm{~b} 5$ & 6 & 100 \\
\hline
\end{tabular}

\begin{tabular}{|c|c|}
\hline Your Package \# & 1 \\
\hline Standby \# & 3 \\
\hline Best Price & 300 \\
\hline
\end{tabular}

You can use the cursor to move around the screen.

The Upper Window (Brown) allows you to enter a bid or place an offer on the standby queue for any package which has value to you. The first column, labelled Standby, is used to indicate whether you wish to make a bid for a package or to send an offer to the standby queue. The second column, entitled Bid, displays the amount in francs of your bid or offer. The third column, entitled Package \#, indicates the number of the package which you are bidding or making an offer for. The number corresponds to the package \# as listed in the purple window.

The Left Window (Purple) - lists packages which have value to you. The first column, entitled \#, lists the number of the package. The second column, labelled Package, lists the slots contained in the package. The third column, labelled Status, lists the current status of the last bid you sent to the market for the package. Your current status may be:

Accepted - You have the current standing bid.

Bumped - Someone has bid higher than you for a package that overlaps which your package. 
Standby - You have entered an offer on the standby queue.

You may also have nothing written in the status column for a particular package. That means that you have not sent a bid to the market for some time.

The Right Upper Window (Dark Blue) - lists all outstanding offers on the standby queue by:

a) items in the package.

b) identification number of the person who made the offer.

c) amount of money offered.

The first column, entitled \#, gives the number of the offer. Each participant make have up to two offers outstanding on the standby queue. The second column, labelled package, lists the slots in the package. The third column, entitled subject, gives the ID number of the participant who placed the offer. The fourth column, entitled $\mathbb{S}$, gives the amount (in francs) of the offer.

The Lower Right Window - Allows you to combine with other offers on the standby queue to get a bid accepted. The first row, entitled your package number, indicates the package which you are bidding on, as it is listed in the purple window. The second row, labelled Standby \#, gives the number of the offer on the standby queue (the dark blue window) with which you are combining. The third row, entitled Best Price, gives you the lowest amount of francs you would need to spend to receive the package specified in row 1 if you combine with the package in row 2.

\subsection{Key Functions}

1) There are two ways to enter a bid:

a) Enter a bid and a package number in the upper window, then press [Enter] and [F1] at the same time.

b) Move cursor to package in left window and press [Enter] and [F1] at the same time. This automatically sends a bid to the market for 10 francs 
more than the standing bid.

2) To make an offer on the standby queue:

Enter a $Y$, a bid, and a package number in the Upper Window and press [Enter] and [F1] at the same time.

3) To combine with another offer on the standby queue:

Enter your package number and the number(s) of the offer(s) on the standby queue with which you wish to combine in the lower right window. Type in the amount that you wish to bid in the row labelled best price and press [Enter] and [F2] at the same time to send your bid to the market.

If you press [F4] a number will appear in the Best Price row. This is the least you can bid and still be able to purchase the package. You can then automatically send a bid to the market at the best price by pressing [Enter] and $[\mathrm{F} 2]$ at the same time. 
Table 1. Demander's Valuations: High Contention Condition

\begin{tabular}{|c|c|c|c|c|c|}
\hline$i$ & \multicolumn{3}{|c|}{$s \in P_{j}$} & $V_{i j}$ & $p_{j}$ \\
\hline 1 & $3 a$ & $4 a$ & $5 a$ & 2450 & 2900 \\
\hline 1 & $\overline{3 b}$ & $4 b$ & $\overline{5 b}$ & 1450 & 1450 \\
\hline * 1 & $8 a$ & $9 a$ & $10 a$ & 3150 & 2000 \\
\hline$* 1$ & $8 b$ & $9 b$ & $10 \mathrm{~b}$ & 2150 & 1350 \\
\hline *2 & $4 a$ & $5 a$ & & 3200 & 1800 \\
\hline * 2 & $\overline{4 b}$ & $\overline{5 b}$ & & 2000 & 1200 \\
\hline 2 & $8 a$ & $9 a$ & $10 a$ & 2000 & 2000 \\
\hline 2 & $\overline{8 b}$ & $9 b$ & $10 \mathrm{~b}$ & 1000 & 1350 \\
\hline 3 & $3 a$ & $8 a$ & & 1600 & 1600 \\
\hline 3 & $1 b$ & $\overline{6 b}$ & & 1600 & 1600 \\
\hline *3 & $2 b$ & $7 b$ & & 3200 & 1250 \\
\hline 3 & $3 b$ & $8 b$ & & 1600 & 1600 \\
\hline$* 4$ & $2 a$ & $7 a$ & & 3000 & 2000 \\
\hline 4 & $3 a$ & $8 a$ & & 1500 & 1600 \\
\hline * 4 & 16 & $6 \mathrm{~b}$ & & 1750 & 1600 \\
\hline 4 & $2 b$ & $7 \mathrm{~b}$ & & 1250 & 1250 \\
\hline 4 & $\overline{3 b}$ & $\overline{8 b}$ & & 750 & 1600 \\
\hline
\end{tabular}

\begin{tabular}{|c|c|c|c|c|c|c|}
\hline$i$ & \multicolumn{4}{|c|}{$s \in P_{j}$} & $V_{i j}$ & $p_{j}$ \\
\hline$* 5$ & $3 a$ & $3 b$ & & & 3000 & 1350 \\
\hline 5 & $4 a$ & $4 b$ & $5 a$ & $5 b$ & 3000 & 3000 \\
\hline 5 & $8 a$ & $8 b$ & & & 1500 & 1850 \\
\hline 5 & $9 a$ & $9 b$ & $10 a$ & $10 \mathrm{~b}$ & 1500 & 1500 \\
\hline$* 6$ & la & & & & 750 & 0 \\
\hline 6 & $2 a$ & & & & 1000 & 1000 \\
\hline 6 & $3 a$ & & & & 500 & 1100 \\
\hline *6 & $6 a$ & & & & 750 & 0 \\
\hline 6 & $7 a$ & & & & 1000 & 1000 \\
\hline 6 & $8 a$ & & & & 500 & 500 \\
\hline 6 & $1 b$ & & & & 750 & 850 \\
\hline 6 & $2 b$ & & & & 500 & 750 \\
\hline 6 & $3 b$ & & & & 250 & 250 \\
\hline 6 & $6 b$ & & & & 750 & 750 \\
\hline 6 & $7 b$ & & & & 500 & 500 \\
\hline 6 & $8 b$ & & & & 250 & 1350 \\
\hline & & & & & & \\
\hline
\end{tabular}

The asterisks mark the packages allocated at the optimum. The competitive equilibrium price of package $\mathrm{j}$ is given in the column laballed $\boldsymbol{p}_{\boldsymbol{j}} . \boldsymbol{p}_{\boldsymbol{j}}$ is the sum of the dual prices of the slots comprising the package. 
Table 2. Demander's Valuations: Low Contention Condition

\begin{tabular}{|r|c|c|c|c|c|c|}
\hline$i$ & \multicolumn{3}{|c|}{$s \in P_{j}$} & $V_{i j}$ & $p_{j}$ \\
\hline$* 1$ & $9 \mathrm{a}$ & $10 \mathrm{a}$ & & & 4000 & 1000 \\
\hline 1 & $9 \mathrm{~b}$ & $10 \mathrm{~b}$ & & & 850 & 850 \\
\hline 2 & $9 \mathrm{a}$ & $10 \mathrm{a}$ & & & 1000 & 1000 \\
\hline$* 2$ & $9 \mathrm{~b}$ & $10 \mathrm{~b}$ & & & 4000 & 850 \\
\hline$* 3$ & $1 \mathrm{a}$ & $6 \mathrm{a}$ & & & 3250 & 1600 \\
\hline 3 & $2 \mathrm{a}$ & $7 \mathrm{a}$ & & & 1000 & 1000 \\
\hline$* 3$ & $2 \mathrm{~b}$ & $7 \mathrm{~b}$ & & & 2250 & 0 \\
\hline$* 4$ & $2 \mathrm{a}$ & $7 \mathrm{a}$ & & & 3250 & 1000 \\
\hline 4 & $3 \mathrm{a}$ & $8 \mathrm{a}$ & & & 1000 & 1000 \\
\hline$* 4$ & $1 \mathrm{~b}$ & $6 \mathrm{~b}$ & & & 2750 & 1600 \\
\hline$* 5$ & $4 \mathrm{a}$ & $5 \mathrm{a}$ & $4 \mathrm{~b}$ & $5 \mathrm{~b}$ & 3000 & 0 \\
\hline 5 & $9 \mathrm{a}$ & $10 \mathrm{a}$ & $9 \mathrm{~b}$ & $10 \mathrm{~b}$ & 1000 & 1850 \\
\hline 6 & $1 \mathrm{a}$ & & & & 800 & 800 \\
\hline$* 6$ & $3 \mathrm{a}$ & & & & 1200 & 1000 \\
\hline 6 & $6 \mathrm{a}$ & & & & 800 & 800 \\
\hline$* 6$ & $8 \mathrm{a}$ & & & & 1000 & 0 \\
\hline 6 & $1 \mathrm{~b}$ & & & & 800 & 800 \\
\hline$* 6$ & $3 \mathrm{~b}$ & & & & 1000 & 0 \\
\hline 6 & $6 \mathrm{~b}$ & & & & 800 & 800 \\
\hline$* 6$ & $8 \mathrm{~b}$ & & & & 1000 & 0 \\
\hline
\end{tabular}

The asterisks mark the packages allocated at the optimum. The $p_{j}$ indicate the competitive equilibrium prices of the packages.

Table 3. Dual (Competitive Equilibrium) prices for all slots: High Contention

\begin{tabular}{|c|c|c|c|c|c|c|c|c|c|c|}
\hline Resources & \multicolumn{10}{|c|}{ Time } \\
\hline & 1 & 2 & 3 & 4 & 5 & 6 & 7 & 8 & 9 & 10 \\
\hline $\mathrm{a}$ & 0 & 1000 & 1100 & 1800 & 0 & 0 & 1000 & 500 & 1500 & 0 \\
\hline $\mathrm{b}$ & 850 & 750 & 250 & 1200 & 0 & 750 & 500 & 1350 & 0 & 0 \\
\hline
\end{tabular}


Table 4. Dual (Competitive Equilibrium) prices for all slots: Low Contention

\begin{tabular}{|c|c|c|c|c|c|c|c|c|c|c|}
\hline Resources & \multicolumn{10}{|c|}{ Time } \\
\hline & 1 & 2 & 3 & 4 & 5 & 6 & 7 & 8 & 9 & 10 \\
\hline $\mathrm{a}$ & 800 & 1000 & 1000 & 0 & 0 & 800 & 0 & 0 & 1000 & 0 \\
\hline $\mathrm{b}$ & 800 & 0 & 0 & 0 & 0 & 800 & 0 & 0 & 850 & 0 \\
\hline
\end{tabular}

Table 5: Initial Endowment of Tokens

\begin{tabular}{|c||c|c|c|c|c|c|}
\hline \multicolumn{1}{|c||}{} & \multicolumn{7}{c|}{ Low Contention } \\
\hline Demander & 1 & 2 & 3 & 4 & 5 & 6 \\
\hline Equal Endowment & 1000 & 1000 & 1000 & 1000 & 1000 & 1000 \\
\hline Comp. Endowment & 1000 & 850 & 1600 & 1800 & 5 & 1000 \\
\hline & \multicolumn{8}{|c|}{ High Contention } \\
\hline Demander & 1 & 2 & 3 & 4 & 5 & 6 \\
\hline Equal Endowment & 1000 & 1000 & 1000 & 1000 & 1000 & 1000 \\
\hline Comp Endowment & 1825 & 1500 & 625 & 1800 & 675 & 5 \\
\hline
\end{tabular}

Table 6. Information about Experimental Sessions

\begin{tabular}{|c|c|c|c|}
\hline Exp. Number. & Mechanism & H/L Contention & Num. Periods \\
\hline 1 & Committee & H & 10 \\
\hline 2 & Committee & H & 9 \\
\hline 3 & AUSM & H & 9 \\
\hline 4 & AUSM & H & 11 \\
\hline 5 & AUSM/tokens & H & $8(3 / 5)$ \\
\hline 6 & AUSM/tokens & H & $11(8 / 3)$ \\
\hline 7 & Committee & L & 8 \\
\hline 8 & Committee & $\mathrm{L}$ & 10 \\
\hline 9 & AUSM & L & 10 \\
\hline 10 & AUSM & L & 10 \\
\hline 11 & AUSM/tokens & L & $9(6 / 3)$ \\
\hline 12 & AUSM/tokens & L & $12(7 / 5)$ \\
\hline
\end{tabular}


Table 7. Allocative Efficiency and Cost to Users of the Three Mechanisms

\begin{tabular}{|c|c|c|c|c|c|c|}
\hline $\begin{array}{c}\text { Dependent } \\
\text { Variable }\end{array}$ & One & Period & Hicon & Compendow & $R^{2}$ & $\mathrm{n}$ \\
\hline $\begin{array}{l}\text { Efficiency } \\
\text { Committee }\end{array}$ & $\begin{array}{c}80.434 \\
(3.038)\end{array}$ & $\begin{array}{l}1.546 \\
(0.515)\end{array}$ & $\begin{array}{r}-19.100 \\
(2.520)\end{array}$ & & .65 & 37 \\
\hline $\begin{array}{c}\text { Efficiency } \\
\text { AUSM/Money }\end{array}$ & $\begin{array}{l}85.916 \\
(3.398)\end{array}$ & $\begin{array}{c}1.324 \\
(0.486)\end{array}$ & $\begin{array}{c}-3.096 \\
(2.634)\end{array}$ & & .20 & 40 \\
\hline $\begin{array}{c}\text { Efficiency } \\
\text { AUSM/Tokens }\end{array}$ & $\begin{array}{l}80.317 \\
(5.815)\end{array}$ & $\begin{array}{l}1.035 \\
(0.636)\end{array}$ & $\begin{array}{c}6.216 \\
(3.328)\end{array}$ & $\begin{array}{l}0.400 \\
(2.63)\end{array}$ & .14 & 40 \\
\hline $\begin{array}{c}\text { User Cost } \\
\text { Committee }\end{array}$ & $\begin{array}{c}6.23 \\
(1.36)\end{array}$ & $\begin{array}{l}-0.702 \\
(0.255)\end{array}$ & $\begin{array}{l}5.94 \\
(1.30)\end{array}$ & & .44 & 37 \\
\hline $\begin{array}{c}\text { User Cost } \\
\text { AUSM/Money }\end{array}$ & $\begin{array}{r}16.20 \\
(4.45)\end{array}$ & $\begin{array}{c}1.54 \\
(0.731)\end{array}$ & $\begin{array}{l}21.10 \\
(3.65)\end{array}$ & & .55 & 40 \\
\hline
\end{tabular}

( ) are standard errors. 
Table 8. Efficiency and User Surplus: Committee Process

\begin{tabular}{||c||c|c|c|c||}
\hline & L1 & L10 & H1 & H10 \\
\hline Effic. & $81.98(16.44)$ & $95.89(71.06)$ & $62.88(1.21)$ & $76.79(25.77)$ \\
\hline Cost & 5.53 & -0.79 & 11.47 & 5.15 \\
\hline Users' Surplus & $76.45(11.84)$ & $96.68(71.06)$ & $51.41(0)$ & $71.64(10.1)$ \\
\hline
\end{tabular}

Table 9. Efficiency and User Surplus: AUSM/Money

\begin{tabular}{||c||c|c|c|c||}
\hline & L1 & L10 & H1 & H10 \\
\hline Effic. & $87.24(26.54)$ & $99.16(71.06)$ & $84.14(54.75)$ & $96.06(95.09)$ \\
\hline Cost & 17.74 & 31.60 & 38.84 & 52.70 \\
\hline Users' Surplus & $69.50(1.81)$ & $67.56(1.47)$ & $45.30(0)$ & $43.36(0)$ \\
\hline
\end{tabular}

Table 10. Efficiency and User Surplus: AUSM/tokens/the Equal Endowment Condition

\begin{tabular}{||c||c|c|c|c||}
\hline & L1 & L10 & H1 & H10 \\
\hline Effic. & $81.35(16.44)$ & $90.67(57.25)$ & $87.56(72.71)$ & $96.88(95.09)$ \\
\hline Cost & 0 & 0 & 0 & 0 \\
\hline Users Surplus & $81.35(16.44)$ & $90.67(57.25)$ & $87.56(72.71)$ & $96.88(95.09)$ \\
\hline
\end{tabular}

Table 11. The Effect of the Two Endowments on the Variance of Payoffs Across Subjects

\begin{tabular}{|c|c|c|c|}
\hline Variable & Coefficient & Std. Error & t-stat \\
\hline one & 3404260 & 788676 & 4.316 \\
per & -167333 & 112328 & -1.490 \\
hicon & 712256 & 600223 & 1.187 \\
compendow & 275415 & 648072 & 0.425 \\
\hline \multicolumn{4}{|c}{$R^{2}=.08, \mathrm{n}=40}$.
\end{tabular}


Table 12. Allocated Packages Under AUSM/Tokens Under Both Endowments: High Contention Condition

\begin{tabular}{|c|c|c|c|c|c|c|c|c|c|c|c|c|c|c|}
\hline$i$ & \multicolumn{3}{|c|}{$s \in P_{j}$} & $V_{i j}$ & E.E. & C.E. & $i$ & \multicolumn{4}{|c|}{$s \in P_{j}$} & $V_{i j}$ & E.E. & C.E. \\
\hline$T$ & $3 a$ & $4 a$ & $5 a$ & 2450 & 0 & 0 & $* 5$ & $3 a$ & $3 \mathrm{~b}$ & & & 3000 & 100 & 100 \\
\hline 1 & $\overline{3 b}$ & $4 b$ & $5 b$ & 1450 & 0 & $\overline{0}$ & 5 & $4 a$ & $4 b$ & $5 a$ & $5 b$ & 3000 & 9 & 0 \\
\hline$* 1$ & $8 a$ & $9 a$ & $\overline{10 a}$ & 3150 & 100 & 100 & 5 & $8 \mathrm{a}$ & $8 b$ & & & 1500 & 0 & 0 \\
\hline$* 1$ & $8 \mathrm{~b}$ & $9 \mathrm{~b}$ & $\overline{10 b}$ & 2150 & 91 & 100 & 5 & $9 \mathrm{a}$ & $\overline{9 b}$ & $10 a$ & $10 \mathrm{~b}$ & 1500 & 0 & 0 \\
\hline$* 2$ & $4 a$ & $5 a$ & & 3200 & 91 & 100 & $* 6$ & $1 a$ & & & & 750 & 100 & 100 \\
\hline$* 2$ & $4 b$ & $5 b$ & & 2000 & $\overline{91}$ & 100 & 6 & $\overline{2 a}$ & & & & 1000 & 18 & 0 \\
\hline 2 & $8 a$ & $9 \mathrm{a}$ & $10 a$ & 2000 & 0 & 0 & 6 & $3 \mathrm{a}$ & & & & 500 & 0 & 0 \\
\hline 2 & $8 b$ & $9 b$ & $10 \mathrm{~b}$ & 1000 & 9 & 0 & $* 6$ & $6 \mathrm{a}$ & & & & 750 & 100 & 100 \\
\hline 3 & $3 a$ & $8 a$ & & 1600 & 0 & 0 & 6 & $7 a$ & & & & 1000 & 18 & 0 \\
\hline 3 & $1 b$ & $6 b$ & & 1600 & 9 & 25 & 6 & $8 a$ & & & & 500 & 0 & 0 \\
\hline *3 & $2 b$ & $7 \mathrm{~b}$ & & 3200 & 64 & $\overline{50}$ & 6 & 16 & & & & 750 & 36 & 0 \\
\hline 3 & $\overline{3 b}$ & $8 b$ & & 1600 & 0 & 0 & 6 & $\overline{2 b}$ & & & & 500 & 9 & 0 \\
\hline$* 4$ & $2 a$ & $7 a$ & & $\overline{3000}$ & 82 & 100 & 6 & $3 \mathrm{~b}$ & & & & 250 & 0 & 0 \\
\hline 4 & $3 a$ & $8 a$ & & 1500 & 0 & 0 & 6 & $6 \mathrm{~b}$ & & & & 750 & 36 & 0 \\
\hline$* 4$ & 16 & $6 b$ & & 1750 & 55 & 75 & 6 & $\overline{7 b}$ & & & & 500 & 9 & 0 \\
\hline 4 & $2 b$ & $7 b$ & & 1250 & 27 & 50 & 6 & $8 \mathrm{~b}$ & & & & 250 & 0 & 0 \\
\hline 4 & $\overline{3 b}$ & $8 \mathrm{~b}$ & & 750 & 0 & 0 & & & & & & & & \\
\hline
\end{tabular}

E.E. $=\%$ of periods in which this package was received in the Equal Endowment treatment.

C.E. $=\%$ of periods in which this package was received in the Competitive Endowment treatment. 
Table 13. Allocated Packages Under AUSM/Tokens Under Both Endowments: Low Contention Condition

\begin{tabular}{|c|c|c|c|c|c|c|c|}
\hline$i$ & \multicolumn{4}{|c|}{$s \in P_{j}$} & $V_{i j}$ & E.E. & C.E. \\
\hline$* 1$ & $9 a$ & $10 \mathrm{a}$ & & & 4000 & 85 & 88 \\
\hline 1 & $9 \mathrm{~b}$ & $10 \mathrm{~b}$ & & & 850 & 8 & 25 \\
\hline$\overline{2}$ & $\overline{9 a}$ & $10 \mathrm{a}$ & & & 1000 & 8 & 12 \\
\hline$* 2$ & $\overline{9 b}$ & $10 \mathrm{~b}$ & & & 4000 & 85 & 75 \\
\hline$* 3$ & 1a & $6 a$ & & & 3250 & 85 & 100 \\
\hline 3 & $2 a$ & $7 a$ & & & 1000 & 23 & 12 \\
\hline$* 3$ & $2 b$ & $7 \mathrm{~b}$ & & & 2250 & 100 & 100 \\
\hline$* 4$ & $2 a$ & $7 a$ & & & 3250 & 77 & 88 \\
\hline 4 & $3 a$ & $\overline{8 a}$ & & & 1000 & 15 & 25 \\
\hline$* 4$ & $1 b$ & $6 \mathrm{~b}$ & & & 2750 & 38 & 50 \\
\hline$* 5$ & $4 \mathrm{a}$ & $5 a$ & $4 \mathrm{~b}$ & $5 b$ & 3000 & 100 & 100 \\
\hline 5 & $9 a$ & $10 \mathrm{a}$ & $9 \mathrm{~b}$ & $10 \mathrm{~b}$ & 1000 & 8 & 0 \\
\hline 6 & $1 \mathrm{a}$ & & & & 800 & 15 & 37 \\
\hline$* 6$ & $3 a$ & & & & 1200 & 85 & 75 \\
\hline 6 & $6 a$ & & & & 800 & 15 & 0 \\
\hline$* 6$ & $8 a$ & & & & 1000 & 85 & 75 \\
\hline 6 & $1 \mathrm{~b}$ & & & & 800 & 62 & 50 \\
\hline$* 6$ & $3 \mathrm{~b}$ & & & & 1000 & 100 & 100 \\
\hline 6 & $6 \mathrm{~b}$ & & & & 800 & 62 & 50 \\
\hline$* 6$ & $8 \mathrm{~b}$ & & & & 1000 & 100 & 100 \\
\hline
\end{tabular}


Figure 1. JPL Resource Allocation Negotiation Process

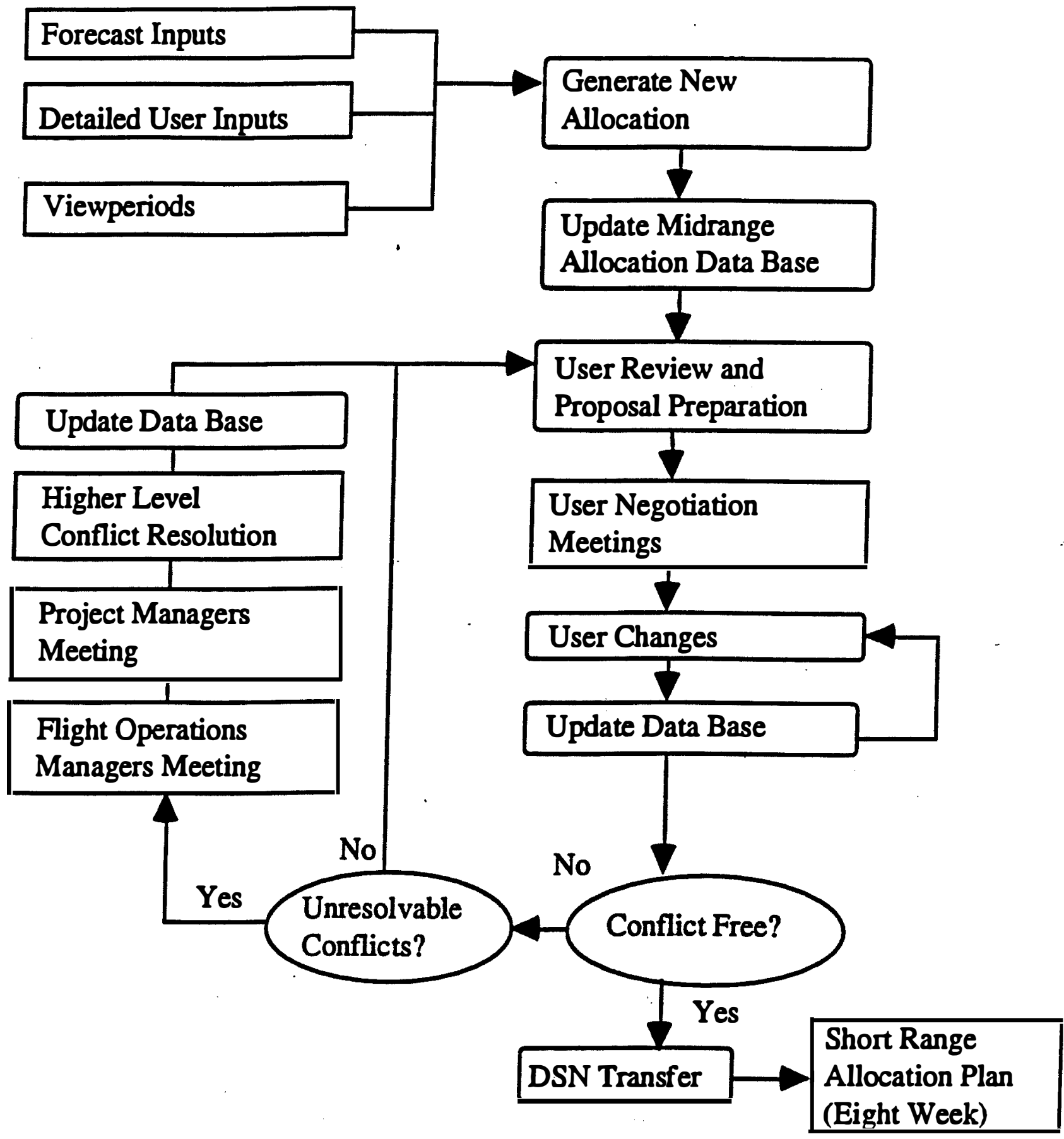


Figure 2. Commodity to be Allocated (20 slots)

\begin{tabular}{|c|c|c|c|c|c|c|c|c|c|c|}
\hline Resources & \multicolumn{10}{|c|}{ Time } \\
\hline & 11 & 2 & 3 & 4 & 5 & 6 & 7 & & 9 & 10 \\
\hline a & & & & & 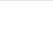 & & & 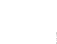 & & \\
\hline b & & & & & & & & & & \\
\hline
\end{tabular}

Figure 3. Users (6)

\begin{tabular}{|c|c|c|c|c|c|c|}
\hline & \multicolumn{6}{|c|}{ User \# } \\
\hline & 1 & $\overline{2}$ & 3 & 4 & 5 & 6 \\
\hline Type & $\bar{C}$ & $\bar{C}$ & $\bar{P}$ & $\bar{P}$ & $\overline{\mathrm{A}}$ & $\overline{\mathrm{M}}$ \\
\hline View period & 1 & 1 & 2 & $\overline{2}$ & 1 & 2 \\
\hline
\end{tabular}

$\mathrm{C}=$ contiguous, $\mathrm{P}=$ periodic, $\mathrm{A}=$ array, $\mathrm{M}=$ maintenance viewperiod $1 \Rightarrow$ usable slots $\in$ columns $3,4,5,8,9,10$ viewperiod $2 \Rightarrow$ usable slots $\in$ columns $1,2,3,6,7,8$ 
Figure 4: Efficiency of Allocations of the Random Algorithm: High Contention Parameters

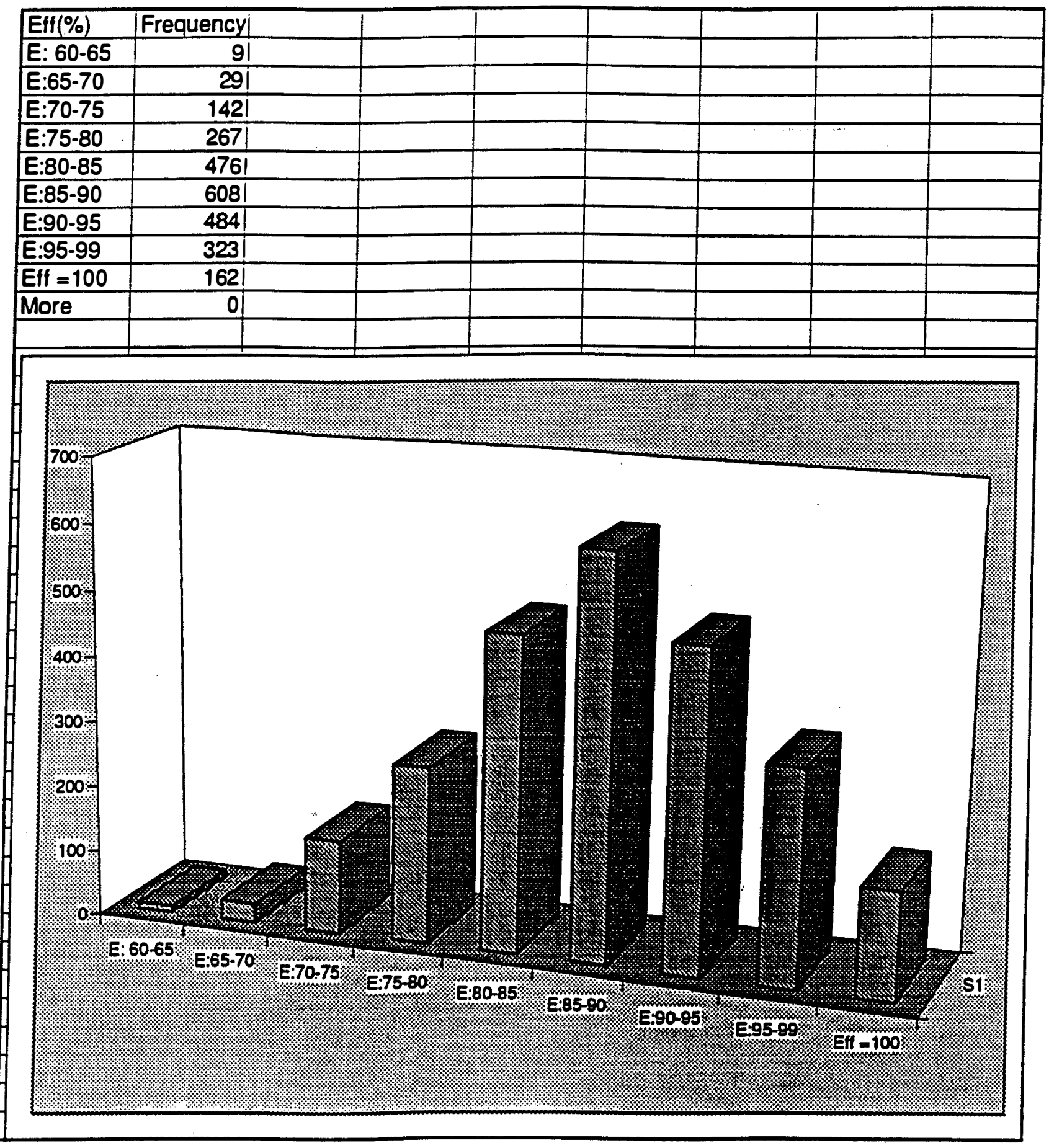


Figure 5: Efficiency of Allocations of the Random Algorithm: Low Contention Paramerers

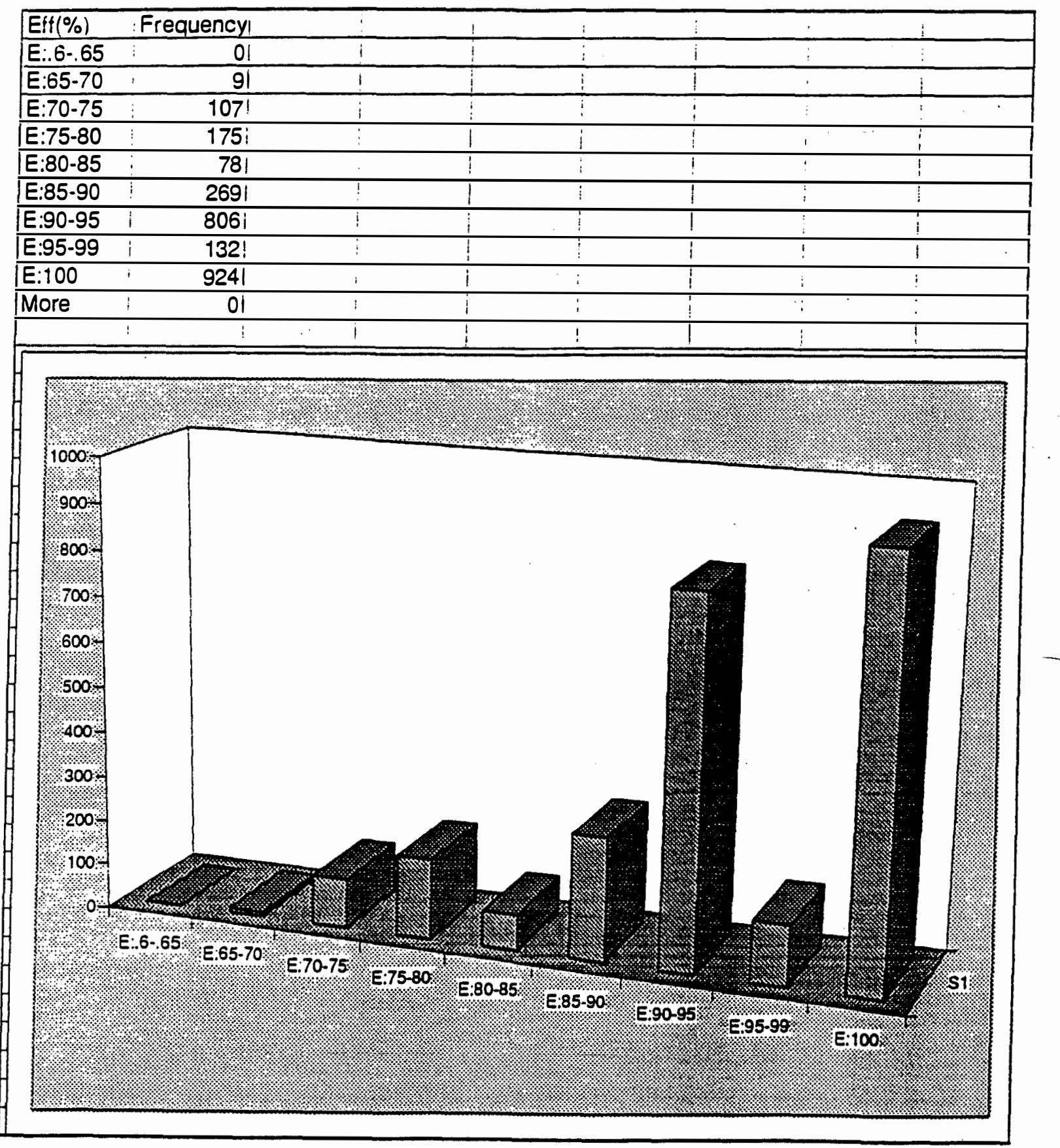




\section{References}

Banks, J.S., J.O. Ledyard, and D.P. Porter (1989). "Allocating uncertain and unresponsive resources: an experimental approach," RAND Journal of Economics, 20:1-25.

Grether, D.M., R.M. Isaac, and C.R. Plott (1981). "The allocation of landing rights by unanimity among competitors," American Economic Review Proceedings, 71:166-171.

Koopmans, T.C. and M.J. Beckman (1957). "Assignment Problems and the Location of Economic Activities," Econometrica; 25:53-76.

Ledyard, John (1993). "The Design of Coordination Mechanisms and Organizational Computing," Journal of Organizational Computing, 3(1), pp. 121-134.

Ledyard, John (1994). "Public Goods: A Survey of Experimental Research," Social Science Working Paper No. 861, California Institute of Technology. 'To appear in Handbook of Experimental Economics, edited by A. Roth and J. Kagel, Princeton University Press.

Olson, Mark (1991). "Dominant and Nash Strategy Mechanisms for the Assignment Problem," Social Science Working Paper No. 770, California Institute of Technology.

Olson, M. and D. Porter (1991). "A Deep Space Resource Allocation Primer," California Institute of Technology mimeo.

Olson, M. and D. Porter (1994). "An experimental examination into the design of decentralized methods to solve the assignment problem with and without money," Economic Theory, 4:11-40.

Ostrom, Elinor (1990). "Governing the Commons," Cambridge: Cambridge University Press.

Papai, S. (1994). “Assignment by Design," mimeo, California Institute of Technology. 
Riker, W.H. and I. Sened (1991). "A Political Theory of the Origin of Property Rights: Airport Slots," American Journal of Political Science, Vol. 35, No. 4: 951-969.

Sened, I. and W.H. Riker (1992). "Common Property and Private Property: The Case of Air Slots," mimeo, Tel Aviv University, November 1992.

Smith, V. (1976). "Experimental Economics: Induced Value Theory," American Economic Review, 66:274-279. 